Revista Brasil. Bot., V.33, n.1, p.61-83, jan.-mar. 2010

\title{
Cianobactérias de diferentes tipos de lagoas ("salina", "salitrada" e "baía") representativas do Pantanal da Nhecolândia, MS, Brasil"
}

\author{
KLEBER RENAN DE SOUZA SANTOS ${ }^{2,3}$ e CÉLIA LEITE SANT’ANNA²
}

(recebido: 18 de fevereiro de 2009; aceito: 23 de dezembro de 2009)

\begin{abstract}
Cyanobacteria from different types of lakes ("salina", "salitrada" and "baía") representative of the Pantanal da Nhecolândia, MS, Brazil). Considering the ecological importance of cyanobacteria and the scarcity of more precise information about these organisms in the different aquatic systems of the Brazilian Pantanal, our aim is the study of the cyanobacterial flora in three lakes in the Pantanal da Nhecolândia region. The studied lakes are natural water bodies and are shallow (maximum depth $1.1 \mathrm{~m}$ ), rounded and present different limnological features mainly regardin to the $\mathrm{pH}$ and salinity. The samples were collected in the dry and rainy seasons, during 2004-2007. Twenty one species of cyanobacteria were identified. Oscillatoriales was the order with the highest species richness ( $24 \%$ of the total of the identified species), followed by Synechococcales, Pseudanabaenales, Chroococcales and Nostocales, each one contributing with 19\%. The lake "Salina do Meio" presents extreme environmental conditions and was the highest species richness system for cyanobacterial ( 13 species $-62 \%)$. In this lake, blooms of Anabaenopsis elenkinii Miller were observed, mainly during the dry season. The lakes "Salitrada Campo Dora" (9 species) and "Baía da Sede Nhumirim" (9) presented equals species richness, but the floristic composition was distinct probably due to their different limnological conditions. All the species were referred for the first time to the Brazilian Pantanal.
\end{abstract}

Key words - biodiversity, cyanobacteria, lakes, Pantanal

RESUMO - (Cianobactérias de diferentes tipos de lagoas ("salina", "salitrada" e "baía") representativas do Pantanal da Nhecolândia, MS, Brasil). Diante da importância ecológica das cianobactérias e da escassez de informações mais detalhadas sobre estes organismos nos diversos sistemas aquáticos do Pantanal brasileiro, o objetivo deste trabalho foi estudar a flora de cianobactérias de três lagoas do Pantanal da Nhecolândia. As lagoas estudadas são corpos d'água naturais, rasos (profundidade máxima 1,1 m), aproximadamente circulares e apresentam características limnológicas distintas. As amostras foram coletadas em períodos de seca e de cheia, entre 2004 e 2007. Foram identificadas 21 espécies de cianobactérias, com predominância da ordem Oscillatoriales (24\% do total de espécies), seguida das ordens Synechococcales, Pseudanabaenales, Chroococcales e Nostocales, cada uma contribuindo com 19\%. A lagoa Salina do Meio, de condições ambientais extremas, apresentou maior número de espécies de cianobactérias, 13 (62\%). Nesta lagoa, florações de Anabaenopsis elenkinii Miller foram observadas principalmente nos períodos de seca. As lagoas Salitrada Campo Dora (9 espécies) e Baía da Sede Nhumirim (9) apresentaram riqueza de espécies iguais entre si, porém com composição distinta, provavelmente relacionada às diferentes condições ambientais das lagoas. Todas as espécies são citadas pela primeira vez para o Pantanal brasileiro.

Palavras-chave - biodiversidade, cianobactérias, lagoas, Pantanal

\section{Introdução}

O Pantanal é uma das maiores planícies inundáveis do planeta, com área aproximada de $140.000 \mathrm{~km}^{2} \mathrm{em}$ território brasileiro, localizado nos Estados de Mato Grosso (35\%) e Mato Grosso do Sul (65\%) (Silva \& Abdon 1998).

A sub-região do Pantanal da Nhecolândia (MS) caracteriza-se pela riqueza de lagoas rasas, predominantemente circulares, em diversos estágios sucessionais que, de acordo com suas características limnológicas diferenciadas, são denominadas regionalmente como

1. Parte da dissertação de mestrado do primeiro autor, Programa de Pós Graduação em Biodiversidade Vegetal e Meio Ambiente, Instituto de Botânica, São Paulo, SP, Brasil.

2. Instituto de Botânica, Seção de Ficologia, Avenida Miguel Estéfano, 3687, 04301-012 São Paulo, SP, Brasil.

3. Autor para correspondência: santoskrs@gmail.com "baías", "salitradas" e "salinas" (Calheiros \& Oliveira 1999). As baías geralmente apresentam $\mathrm{pH}$ levemente ácido a neutro (5-7) e condutividade elétrica variável (média $500 \mu \mathrm{S} \mathrm{cm}^{-1}$ ), sendo habitadas por plantas aquáticas flutuantes e submersas. As salitradas apresentam em geral $\mathrm{pH}$ neutro a levemente alcalino (6,5-8), condutividade elétrica média superior a $1.000 \mu \mathrm{S} \mathrm{cm}^{-1}$ e ocorrência de macroalgas (Characeae) e plantas aquáticas vasculares. Nas salinas as condições são consideradas extremas, o pH é alcalino $(>8)$, a condutividade elevada $\left(>2.000 \mu \mathrm{S} \mathrm{cm}^{-1}\right)$ e não ocorrem plantas aquáticas (Almeida et al. 2003, Brum \& Sousa 1985, Hamilton et al. 1999, Medina-Junior \& Rietzler 2005, Mourão et al. 1988).

Estudos taxonômicos sobre cianobactérias são raros no Pantanal. Provavelmente, Drouet (1938) foi o primeiro trabalho a documentar táxons de cianobactérias coletados na área do Pantanal. Este autor registrou Gloeotrichia natans (Hedw.) Bornet \& Flahault, Fremyella tenera 
(Bornet \& Flahault) De Toni, Scytonema hofmannii Bornet \& Flahault, Lyngbya diguetii Gomont e Oscillatoria formosa Gomont, para o Município de Cáceres, ambos no Estado de Mato Grosso.

Além do trabalho de Drouet (1938), merecem destaque os trabalhos de De-Lamonica-Freire \& Heckman (1996), Oliveira \& Calheiros (2000), Silva et al. (2000) e Domitrovic (2002) que citam alguns táxons de cianobactérias. No entanto, esses trabalhos tratam exclusivamente da distribuição espacial e/ou temporal do fitoplâncton principalmente no Pantanal Norte (Cáceres, Poconé e Barão de Melgaço), no Rio Paraguai (MT e MS) e no Canal do Tamengo (MS), não apresentando descrições ou ilustrações dos táxons encontrados.

Especificamente para o Pantanal da Nhecolândia, são conhecidos apenas dois trabalhos com referência à composição de cianobactérias das lagoas desta região. Santos et al. (2004) estudaram três lagoas salinas e uma salitrada e observaram que as cianobactérias são dominantes nas salinas, sendo o gênero Anabaenopsis (Wolosz.) Miller o mais comum nessas lagoas. O trabalho de Malone et al. (2007) refere-se ao levantamento dos gêneros de algas do plâncton de duas lagoas salinas da Fazenda Nhumirim e demonstra também a dominância de cianobactérias nessas lagoas. Ambos os trabalhos apresentam apenas listagem dos gêneros encontrados, sem ilustração ou descrição dos táxons observados. Assim, com relação à biodiversidade de cianobactérias das lagoas da Nhecolândia, inexistem publicações efetivas sobre a composição florística desses ambientes.

Considerando que o conhecimento sobre a biodiversidade é fundamental para projetos de manejo e conservação, o objetivo do presente estudo foi realizar levantamento taxonômico das cianobactérias que ocorrem em três tipos de lagoas consideradas representativas do Pantanal da Nhecolândia: salina, salitrada e baía.

\section{Material e métodos}

Foram estudadas três lagoas representativas das diferentes fisionomias de lagoas da Nhecolândia: Salina do Meio (18 $58^{\prime} 29^{\prime \prime}$ S e $56^{\circ} 38^{\prime} 47^{\prime \prime}$ W), Salitrada Campo Dora $\left(18^{\circ} 58^{\prime} 02^{\prime \prime}\right.$ S e $\left.56^{\circ} 38^{\prime} 59^{\prime \prime} \mathrm{W}\right)$; e Baía da Sede Nhumirim $\left(18^{\circ} 59^{\prime} 37^{\prime \prime} \mathrm{S}\right.$ e $\left.56^{\circ} 37^{\prime} 14^{\prime \prime} \mathrm{W}\right)$. A primeira e a terceira estão localizadas na área da Fazenda Nhumirim (Embrapa Pantanal) e a segunda localiza-se na área da Fazenda Campo Dora, que faz divisa com a Fazenda Nhumirim (figura 1). A Fazenda Nhumirim possui 4.390 ha de área, localiza-se na região centro-oeste do Pantanal da Nhecolândia (Município de Corumbá, MS), onde são encontradas as unidades de paisagem representativas desta sub-região (Embrapa 1997). Somente na área da Fazenda Nhumirim ocorrem cerca de 100

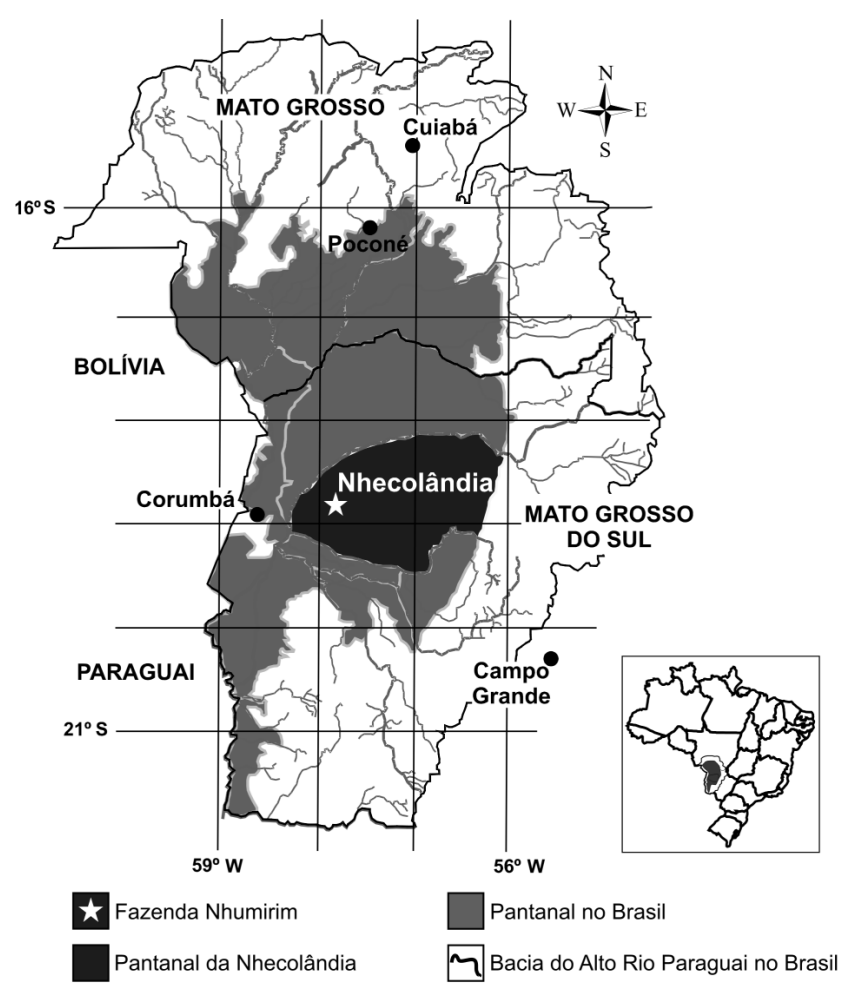

Figura 1. Localização das lagoas estudadas no Pantanal da Nhecolândia, MS, Brasil (modificado de Silva \& Abdon 1998).

Figure 1. Location of the studied lakes from Pantanal da Nhecolândia, Mato Grosso do Sul State, Brazil (modified from Silva \& Abdon 1998).

lagoas, três delas consideradas salinas (Mourão et al. 1988). De acordo com Soriano (1999), o clima na região da Fazenda Nhumirim é do tipo Awa: tropical de altitude, megatérmico (a temperatura média do mês mais frio é superior a $18^{\circ} \mathrm{C}$ ), com duas estações contrastantes, sendo que os meses de novembro a março são caracterizados como época chuvosa, enquanto o período de abril a outubro é considerado de seca. A temperatura média anual é de $25,5^{\circ} \mathrm{C}$ e a precipitação média anual é de 1.182,7 mm.

A Baía da Sede Nhumirim apresenta grandes concentrações de macrófitas aquáticas por toda margem, representadas principalmente por "cana-do-brejo" (Cana glauca L.), "alface-d'água" (Pistia stratiotes L.) e "aguapés" (Eichhornia spp.), ocorrem peixes e a coloração de suas águas é avermelhada devido à matéria orgânica em decomposição. A Salitrada Campo Dora tem formato oitavado alongado, as águas são transparentes, não há ocorrência de peixes e, dentre as macrófitas presentes, destacam-se espécies de Chara L. (Characeae). Por fim, a Salina do Meio tem formato arredondado, a coloração de suas águas varia do marrom acastanhado ao verde azulado e não apresenta macrófitas e peixes. Descrições detalhadas da área de estudo são encontradas em Santos (2008). 
As coletas foram realizadas em períodos de cheia e de seca, entre maio de 2004 e maio de 2007 , totalizando 23 amostras. Para coleta utilizou-se rede de plâncton ( $20 \mu \mathrm{m}$ de abertura de malha) ou garrafa tipo Van-dorn e as amostras foram fixadas no campo com Transeau (1:1) ou formaldeído $4 \%$. Amostras sem adição de fixador foram armazenadas sob refrigeração para posterior estudo de material vivo. O material examinado encontra-se depositado no Herbário Cientifico do Estado "Maria Eneyda P. Kauffmann Fidalgo" do Instituto de Botânica (SP). As amostras foram estudadas sob microscópio óptico binocular Zeiss, modelo Axioplan-2, com sistema de captura de imagens, câmara clara, ocular micrometrada e sistema de epifluorescência acoplados.

A identificação dos táxons foi, sempre que possível, baseada no exame de amostras populacionais. Para destacar a presença de mucilagem foram confeccionadas lâminas com adição de nanquim. Sempre que possível, efetuou-se medidas de interesse taxonômico em 30 indivíduos de cada táxon.
As abreviações usadas no texto são: compr. = comprimento, larg. $=$ largura, diâm. $=$ diâmetro, alt. = altura e Rc/l = razão comprimento/largura. O sistema de classificação adotado foi o de Hoffmann et al. (2005).

A distribuição geográfica no Pantanal brasileiro (conforme delimitação de Silva \& Abdon 1998) foi feita com base em levantamento bibliográfico considerando-se apenas os trabalhos com descrição e/ou ilustração que permitissem comparações.

\section{Resultados e discussão}

Algumas características morfométricaselimnológicas das lagoas estudadas estão apresentadas nas tabelas $1 \mathrm{e}$ 2 respectivamente. Todos os táxons documentados são citados pela primeira vez para o Pantanal brasileiro. Ilustrações desses táxons são apresentadas em pranchas de desenhos (figuras 2 a 17) e fotos (figuras 18 a 62).

Tabela 1. Características morfométricas das lagoas estudadas do Pantanal da Nhecolândia, Estado do Mato Grosso do Sul, Brasil.

Table 1. Morphometric characteristics of studied lakes from Pantanal da Nhecolândia, Mato Grosso do Sul State, Brazil.

\begin{tabular}{|c|c|c|c|}
\hline & $\begin{array}{l}\text { Salina do Meio } \\
\text { (Mourão 1989) }\end{array}$ & $\begin{array}{l}\text { Salitrada Campo Dora } \\
\text { (Rezende-Filho 2006) }\end{array}$ & $\begin{array}{l}\text { Baía da Sede Nhumirim } \\
\text { (presente trabalho) }\end{array}$ \\
\hline Contato com o sistema coalescente & $\begin{array}{l}\text { Nunca ou apenas } \\
\text { excepcionalmente }\end{array}$ & $\begin{array}{l}\text { Nas enchentes } \\
\text { mais expressivas }\end{array}$ & Frequente \\
\hline Comprimento máximo (m) & 436 & 500 & ca. 390 \\
\hline Largura máxima (m) & 325 & 250 & ca. 320 \\
\hline Profundidade máxima (m) & 1,1 & 0,44 & 0,80 \\
\hline Área (ha) & 10,1 & 8 & ca. 8 \\
\hline
\end{tabular}

Tabela 2. Variáveis abióticas das três lagoas estudadas do Pantanal da Nhecolândia, MS, Brasil. Valor médio (máximo e mínimo).

Table 2. Abiotic variables of the studied lakes from Pantanal da Nhecolândia, Mato Grosso do Sul State, Brazil. Numbers are means (maximum and minimum values).

\begin{tabular}{|c|c|c|c|}
\hline & $\begin{array}{l}\text { Salina do Meio } \\
\qquad(n=9)\end{array}$ & $\begin{array}{l}\text { Salitrada } \\
\text { Campo Dora } \\
(n=6)\end{array}$ & $\begin{array}{l}\text { Baía da Sede } \\
\text { Nhumirim } \\
\quad(n=8)\end{array}$ \\
\hline $\mathrm{pH}$ & $9,9(9,04-10,4)$ & $7,9(5,02-9,42)$ & $7,8(7,58-8,06)$ \\
\hline Condutividade elétrica $\left(\mu \mathrm{S} \mathrm{cm}^{-1}\right)$ & $7.951(2.870-19.020)$ & $874(318-1852)$ & $1.421(716-2.110)$ \\
\hline Salinidade (ups) & $4,6(1,4-11,8)$ & $0,2(0,0-0,7)$ & $0,5(0,0-0,9)$ \\
\hline Temperatura da água $\left({ }^{\circ} \mathrm{C}\right)$ & $28,2(21,7-36,1)$ & $27,7(23-32)$ & $28,1(22,1-35,1)$ \\
\hline $\mathrm{O}_{2}$ dissolvido $\left(\mathrm{mg} \mathrm{L}^{-1}\right)$ & $6,8(1,8-10)$ & $5,7(4,6-8,0)$ & $9,1(8,2-10)$ \\
\hline Profundidade $(\mathrm{cm})$ & $33,9(19-64)$ & $33,3(13-44)$ & $32,8(14-80)$ \\
\hline $\begin{array}{l}\text { Desaparecimento do disco } \\
\text { de Sechii }(\mathrm{cm})\end{array}$ & $3,3(1,2-4,0)$ & $27(2-44)$ & $17,3(5-48)$ \\
\hline
\end{tabular}


Chave para as cianobactérias encontradas nas lagoas estudadas

1. Talo unicelular ou colonial

2. Indivíduos coloniais; colônia oca formada por células ovais

Coelomoron tropicale

2. Indivíduos isolados ou aos pares; células fusiformes, esféricas ou alongadas

3. Células fusiformes, extremidades agudas $(0,7-1,5 \mu \mathrm{m}$ larg. $)$

Myxobaktron sp.

3. Células cilíndricas, esféricas ou alongadas $(>1,5 \mu \mathrm{m}$ larg.)

4. Células esféricas

Synechocystis aquatilis

4. Células alongadas

5. Células retas, 2-3,4 $\mu \mathrm{m}$ compr. Synechococcus cf. nidulans

5. Células curvas ou sigmóides, 4,9-16,8(26,6) $\mu \mathrm{m}$ compr. Synechococcus sigmoideus

1. Talo filamentoso

6. Tricomas homocitados

7. Tricomas espiralados

8. Tricomas com septos evidentes, aerótopos presentes

Arthrospira platensis

8. Tricomas com septos inconspícuos, aerótopos ausentes

9. Espiras não agregadas entre si, distantes uma das outras

Glaucospira sp.

9. Espiras agregadas entre si, tocando-se ou não uma na outra

10. Tricomas densamente espiralados, espiras tocando-se em toda

extensão

Spirulina subsalsa

10. Tricomas frouxamente espiralados, espiras não se tocando

Spirulina subtilissima

7. Tricomas retos ou levemente curvos

11. Células mais longas que largas

12. Tricomas irregularmente curvos, curtos (em geral até 8 células)

13. Tricomas com (1)2(3) células, 0,7-1,0 $\mu \mathrm{m}$ larg., células curvas, alongadas $\mathrm{Rc} / 1$ 4-12

Romeria caruaru

13. Tricomas com 2-12(19) células, 0,9-1,2 $\mu \mathrm{m}$ larg., células retas, curtas Rc/1 1,6-3,9

Romeria victoriae

12. Tricomas retos, longos (mais que 10 células)

14. Tricomas móveis, constritos

Pseudanabaena limnetica

14. Tricomas imóveis, não constritos

Jaaginema subtilissimum

11. Células mais curtas que largas

15.Aerótopos presentes

16. Tricomas com ápice gradativamente atenuado; célula apical cônica arredondada Planktothrix agardhii

16. Tricomas não atenuados ou apenas levemente nas extremidades; célula apical cilíndrica arredondada Planktothrix isothrix

15.Aerótopos ausentes

17. Tricomas com grânulos nos septos

Phormidium tergestinum

17. Tricomas sem grânulos nos septos

Phormidium sp.

6. Tricomas heterocitados

18. Tricomas heteropolares, nitidamente atenuados para o ápice, heterocito basal

esférico

Calothrix cf. flahaultii

18. Tricomas isopolares, atenuados ou não, heterocitos terminais ou intercalares

19. Heterocitos intercalares, distribuídos mais ou menos regularmente ao longo do tricoma

Aphanizomenon/Anabaena

19. Heterocitos originando-se de célula intercalar e, posteriormente, tornando-se terminais pela quebra do tricoma

20. Tricomas geralmente retos, sem aerótopos Anabaenopsis cunningtonii 20.Tricomas geralmente curvos ou espiralados, com aerótopos Anabaenopsis elenkinii 


\section{SYNECHOCOCCALES}

\section{MERISMOPEDIACEAE}

Coelomoron tropicale Senna, Peres \& Komárek, Nova Hedwigia 67(1/2): 93-100. 1998.

Figura 2

Colônias irregularmente esféricas a alongadas, 23,9-26,1 $\mu \mathrm{m}$ compr., 17,3-18,5 $\mu \mathrm{m}$ larg.; mucilagem difluente, incolor, visível com auxílio de nanquim; células ovóides, dispostas radialmente, um pouco distantes umas das outras, 2-3,2 $\mu \mathrm{m}$ compr., 1,3-2,5 $\mu \mathrm{m}$ larg.; conteúdo celular verde azulado, homogêneo, sem aerótopos.

Material examinado: BRASIL. Mato Grosso Do Sul: Corumbá, Pantanal da Nhecolândia, Salitrada Campo Dora, 8-V-2005, K.R.S. Santos s.n. (SP390914).

Coelomoron tropicale é uma espécie descrita a partir de material brasileiro coletado em reservatórios do Estado de São Paulo (Senna et al. 1998) e a população do Pantanal está perfeitamente de acordo com a circunscrição original da espécie.

Synechocystis aquatilis Sauv., Bull. Soc. Bot. Fr. 39: 121. 1892.

Figura 18

Células isoladas ou aos pares, arredondadas, 3,7-5,2 $\mu \mathrm{m}$ diâm.; envelope mucilaginoso hialino ou ausente; conteúdo celular verde azulado, geralmente granuloso, sem aerótopos.

Material examinado: BRASIL. Mato Grosso DO Sul: Corumbá, Pantanal da Nhecolândia, Salina do Meio, 25-IX-2005, K.R.S. Santos s.n. (SP390917), 22-IV-2006, K.R.S. Santos s.n. (SP390919), 28-VIII-2006, K.R.S. Santos s.n. (SP390922); Salitrada Campo Dora, 14-VIII-2004, A.Y. Sakamoto \& V.M. Bacani s.n. (SP390909), 21-IV-2006, K.R.S. Santos s.n. (SP390920).

\section{SYNECHOCOCCACEAE}

Synechococcus cf. nidulans (Pringsheim) Komárek, in Bourrely, Les algues D'eau Douce, 3: 119. 1970. $\equiv$ Lauterbornia nidulans Pringsheim, Arch. Mikrobiol. 63: 1-6. 1968.

Figura 19

Células isoladas ou aos pares, raramente 4 células juntas, alongadas, retas, 2-3,4 $\mu \mathrm{m}$ compr., 1,2-2,4 $\mu \mathrm{m}$ larg.; envelope mucilaginoso ausente; conteúdo celular verde azulado, homogêneo, sem aerótopos.

Material examinado: BRASIL. Mato Grosso do Sul: Corumbá, Pantanal da Nhecolândia, Salina do Meio, 25-IX-2005, K.R.S. Santos \& C.F.S. Malone s.n.
(SP390917); 22-IV-2006, K.R.S. Santos s.n. (SP390919); Baía da Sede Nhumirim, 22-IV-2006, K.R.S. Santos s.n. (SP390921); 04-05-2007, K.R.S. Santos s.n. (SP390929).

De acordo com Komárek \& Anagnostidis (1999), Synechococcus nidulans ocorre no plâncton de pequenos corpos de água doce e mais raramente em grandes lagos, às vezes em massas, sendo conhecida, até aquela ocasião, para regiões temperadas. Conforme os referidos autores, $S$. nidulans apresenta células com 1,5-8,5 $\mu$ m compr. e 0,4-1,3(2,2) $\mu \mathrm{m}$ largura. No Brasil, Honda \& Azevedo (2004) documentaram $S$. nidulans com células de 1,8 a $3,1 \mu \mathrm{m}$ compr. e $0,7-1,0 \mu \mathrm{m}$ larg. a partir de amostras de um lago oligotrófico em São Paulo. O material do Pantanal difere da literatura por apresentar largura celular um pouco superior e ocorrer tanto em ambiente de água doce (Baía da Sede Nhumirim; salinidade 0-0,5 ups) como salobra (Salina do Meio; salinidade $1,4-11,8$ ups).

A população estudada assemelha-se morfologicamente a S. elongatus (Nägeli) Nägeli. No entanto, essa espécie ocorre em ambiente subaerofítico, solo, parede de aquários e na região supralitorânea de lagoas (Komárek \& Anagnostidis 1999), enquanto os espécimes estudados ocorreram no plâncton e metafíton, o que está de acordo com o documentado para $S$. nidulans.

Synechococcus sigmoideus (Moore \& Carter) Komárek, Arch. Protistenk. 112: 363. 1970. $\equiv$ Rhabdoderma sigmoideum Moore \& Carter, Ann. Missouri Bot. Gard. 10: 398, Taf. 21, fig. 1. 1923.

Figura 3-4

Células isoladas, cilíndricas, alongadas, curvas ou sigmóides, 4,9-16,8(-26,6) $\mu \mathrm{m}$ compr., 1,5-3,1 $\mu \mathrm{m}$ larg.; envelope mucilaginoso ausente; conteúdo celular verde azulado, homogêneo, sem aerótopos.

Material examinado: BRASIL. Mato Grosso Do Sul: Corumbá, Pantanal da Nhecolândia, Salina do Meio, 25-IX-2005, K.R.S. Santos s.n. (SP390917); 22-IV-2006, K.R.S. Santos s.n. (SP390919); Baía da Sede Nhumirim, 25-IX-2005, K.R.S. Santos \& C.F.S. Malone s.n. (SP390918); 22-IV-2006, K.R.S. Santos s.n. (SP390921).

De acordo com Geitler (1932), Synechococcus sigmoideus (citado como Rhabdoderma sigmoidea) apresenta células sigmóides, 4-13 $\mu \mathrm{m}$ compr., 2-3 $\mu \mathrm{m}$ largura, hábito planctônico e foi descrita originalmente para lagos do Norte de Dakota (Estados Unidos). Geiltler (1932) reconheceu ainda Rhabdoderma sigmoidea $\mathrm{f}$. 



Figuras 2-11.2. Coelomoron tropicale. 3-4. Synechococcus sigmoideus. 5. Myxobaktron sp. 6. Romeria caruaru. 7. Jaaginema subtilissimum. 8-11. Arthrospira platensis. Barras $=10 \mu \mathrm{m}$.

Figures 2-11. 2. Coelomoron tropicale. 3-4. Synechococcus sigmoideus. 5. Myxobaktron sp. 6. Romeria caruaru. 7. Jaaginema subtilissimum. 8-11. Arthrospira platensis. Bars $=10 \mu \mathrm{m}$. 




13
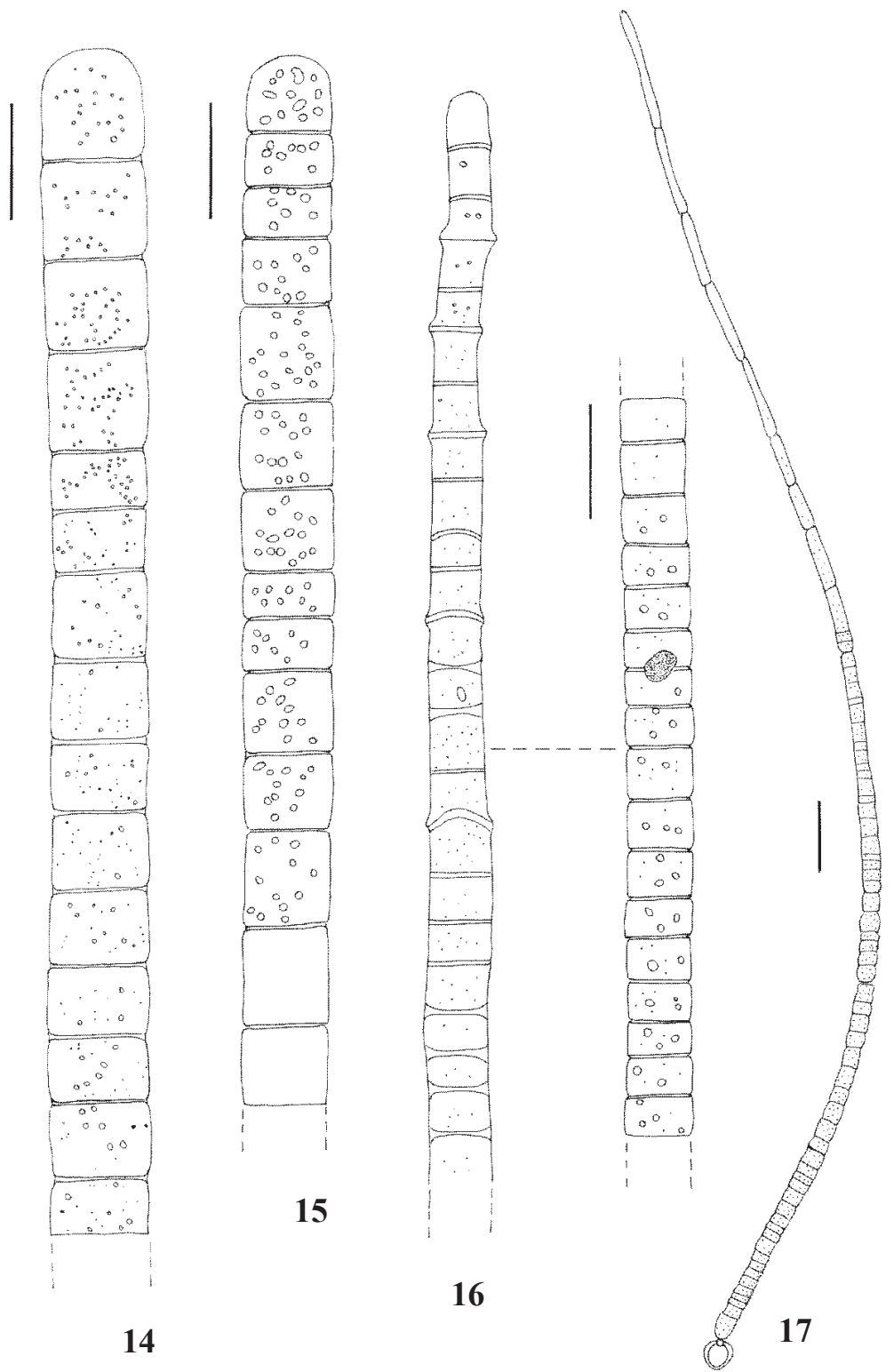

Figuras 12-17. 12-16. Phormidium sp. 12-13. Tricomas com protoplasma diferenciado. 13. Tricoma com necrídio (seta). 12-16. Variação da intensidade de granulações e ápices dos tricomas. 17. Calothrix cf. flahaultii. Barras $=10 \mu \mathrm{m}$.

Figures 12-17. 12-16. Phormidium sp. 12-13. Trichomes with differentiated cell content. 13. Trichome with necridic cell (arrow). 12-16. Variation of cell content granulation and of trichomes apex. 17. Calothrix cf. flahaultii. Bars $=10 \mu \mathrm{m}$.

minor Carter com células de 5-10 $\mu \mathrm{m}$ compr. e 1,5 $\mu \mathrm{m}$ largura.

Autores posteriores consideraram as formas propostas por Moore \& Carter em 1923 (citado por Geitler 1932), como representantes da variação morfométrica de S. sigmoideus (Komárek \& Anagnostidis 1999). Assim, de acordo com Komárek \& Anagnostidis (1999), $S$. sigmoideus apresenta as seguintes dimensões celulares: 4-13 $\mu \mathrm{m}$ compr., 1,5-3 $\mu \mathrm{m}$ larg. Esses autores não mencionam características dos lagos onde a espécie foi encontrada. No Brasil, Delazari-Barroso et al. (2007) documentaram, para o reservatório Duas Bocas no Estado do Espírito Santo, S. sigmoideus com células que variaram de 9-9,6 $\mu \mathrm{m}$ compr. e 1,7-1,9 $\mu \mathrm{m}$ larg. De modo geral, os exemplares do Pantanal estão de acordo com a circunscrição da espécie documentada em literatura. No entanto, alguns exemplares apresentaram comprimento celular maior $(4,9-16,8(26,6) \mu \mathrm{m})$ que o limite máximo 
já registrado para a espécie, e ocorreram tanto em água doce (Baía da Sede) quanto salobra (Salina do Meio). Observou-se que os exemplares com maiores dimensões celulares (até 26,6 $\mu \mathrm{m}$ compr.) foram encontrados na Baía da Sede Nhumirim no período de cheia (figura 4).

\section{PSEUDANABAENALES}

\section{PSEUDANABAENACEAE}

Jaaginema subtilissimum (De Toni) Anagnostidis \& Komárek, Arch. Hydrobiol. Suppl. 80(1-4), Algol. Studies 50-53: 396. 1988. $\equiv$ Oscillatoria subtilissima De Toni, Syll. Alg. 5: 171. 1907.

Figura 7

Tricomas solitários, longos, até $300 \mu \mathrm{m}$ compr., retos ou levemente curvos, não atenuados, não ou apenas levemente constritos, imóveis; células mais longas que largas, 3-6 $\mu \mathrm{m}$ compr., 1,4-2 $\mu \mathrm{m}$ larg., Rc/1 =1,5-3; conteúdo celular verde azulado, geralmente com centroplasma distinto, sem aerótopos; septos translúcidos, não granulados; células apicais arredondadas, bainha ausente.

Material examinado: BRASIL. Mato Grosso do Sul: Corumbá, Pantanal da Nhecolândia, Salina do Meio, 8-V-2005, K.R.S. Santos s.n. (SP390913).

Jaaginema subtilissimum é morfologicamente semelhante a Geitlerinema amphibium (C. Agardh) Anagnostidis e Pseudanabaena limnetica (Lemmerm.) Komárek. No entanto, G. amphibium e P. limnetica apresentam tricomas móveis, enquanto $J$. subtilissimum possui tricomas imóveis. Além disso, os tricomas de J. subtilissimum não apresentam grânulos nos septos e não possuem constrição, enquanto os tricomas de G. amphibium geralmente apresentam de 1-4 grânulos por septo e os de P. limnetica geralmente são constritos.

Pseudanabaena limnetica (Lemmerm.) Komárek, Acta sci. nat. Mus. Bohem. merid., 14: 161-190. 1974. $\equiv$ Oscillatoria limnetica Lemmerm. Ber. Deutsch. Bot. Ges. 18: 310. 1900.

Figuras 21, 25

Tricomas solitários, retos ou levemente curvos, não atenuados, constritos, móveis; células cilíndricas, mais longas que largas, 3-8 $\mu \mathrm{m}$ compr., 1,2-1,8 $\mu \mathrm{m}$ larg., Rc/1 =2,5-6,7; conteúdo celular verde azulado, homogêneo, sem aerótopos; septos translúcidos, não granulados; células apicais arredondadas; bainha ausente.

Material examinado: BRASIL. Mato Grosso do Sul: Corumbá, Pantanal da Nhecolândia, Salina do Meio,
8-V-2005, K.R.S. Santos s.n. (SP390914); Salitrada Campo Dora, 14-VIII-2004, A.Y. Sakamoto \& V.M. Bacani s.n. (SP390909).

Romeria caruaru Komárek et al., Algol. Studies 103 (Cyanobacterial Research 2), 9-29: 14. fig. 3. 2001. Figura 6

Tricomas solitários, curtos, 6,6-15 $\mu \mathrm{m}$ compr., constritos, irregularmente curvos, raramente retos, (1)2(3) células; células mais longas que largas, cilíndricas, curvas ou quase retas, 2,6-8,5 $\mu \mathrm{m}$ compr., $0,7-1,0 \mu \mathrm{m}$ larg., Rc/1=4-12,1; envelope mucilaginoso inconspícuo, difluente, hialino; conteúdo celular homogêneo, verde azul claro.

Material examinado: BRASIL. Mato Grosso DO Sul: Corumbá, Pantanal da Nhecolândia, Salina do Meio, 25-IX-2005, K.R.S. Santos \& C.F.S. Malone s.n. (SP390917).

Romeria caruaru foi recentemente descrita para um reservatório artificial eutrófico (reservatório Tabocas) no município de Caruaru, Estado de Pernambuco (PE), Brasil (Komárek et al. 2001). De acordo com estes autores, $R$. caruaru difere das espécies de Aphanothece que apresentam células semelhantes, pela formação de pseudofilamentos na primeira enquanto a segunda forma colônia. Os referidos autores comentaram ainda que as populações de Romeria, Aphanothece e Aphanocapsa, comuns no reservatório Tabocas, provavelmente contribuíram com a toxicidade da água deste reservatório durante a tragédia de Caruaru.

Romeria victoriae Komárek \& Cronberg, Nova Hedwigia 73(1-2): 141, fig. 13. 2001.

Figura 20

Tricomas solitários, curtos, 12,2-38,1 $\mu \mathrm{m}$ compr., constritos, retos ou curvos, 2-12(19) células, raramente mais; células mais longas que largas, cilíndricas, 1,6$4 \mu \mathrm{m}$ compr., 0,9-1,2 $\mu \mathrm{m}$ larg., $\mathrm{Rc} / 1$ = 1,6-3,9; envelope mucilaginoso inconspícuo, difluente, hialino; conteúdo celular homogêneo, verde azul claro.

Material examinado: BRASIL. Mato Grosso DO Sul: Corumbá, Pantanal da Nhecolândia, Salina do Meio, 28-VIII-2006, K.R.S. Santos s.n. (SP390922), Baía da Sede Nhumirim, 16-XI-2006, K.R.S. Santos s.n. (SP390926); Fazenda Campo Dora, lagoa: Salitrada Campo Dora, 8-V-2005, K.R.S. Santos s.n. (SP390914).

Romeria victoriae é uma espécie recentemente descrita para a África tropical (Komárek \& Cronberg 2001). De acordo com estes autores, esta espécie foi 

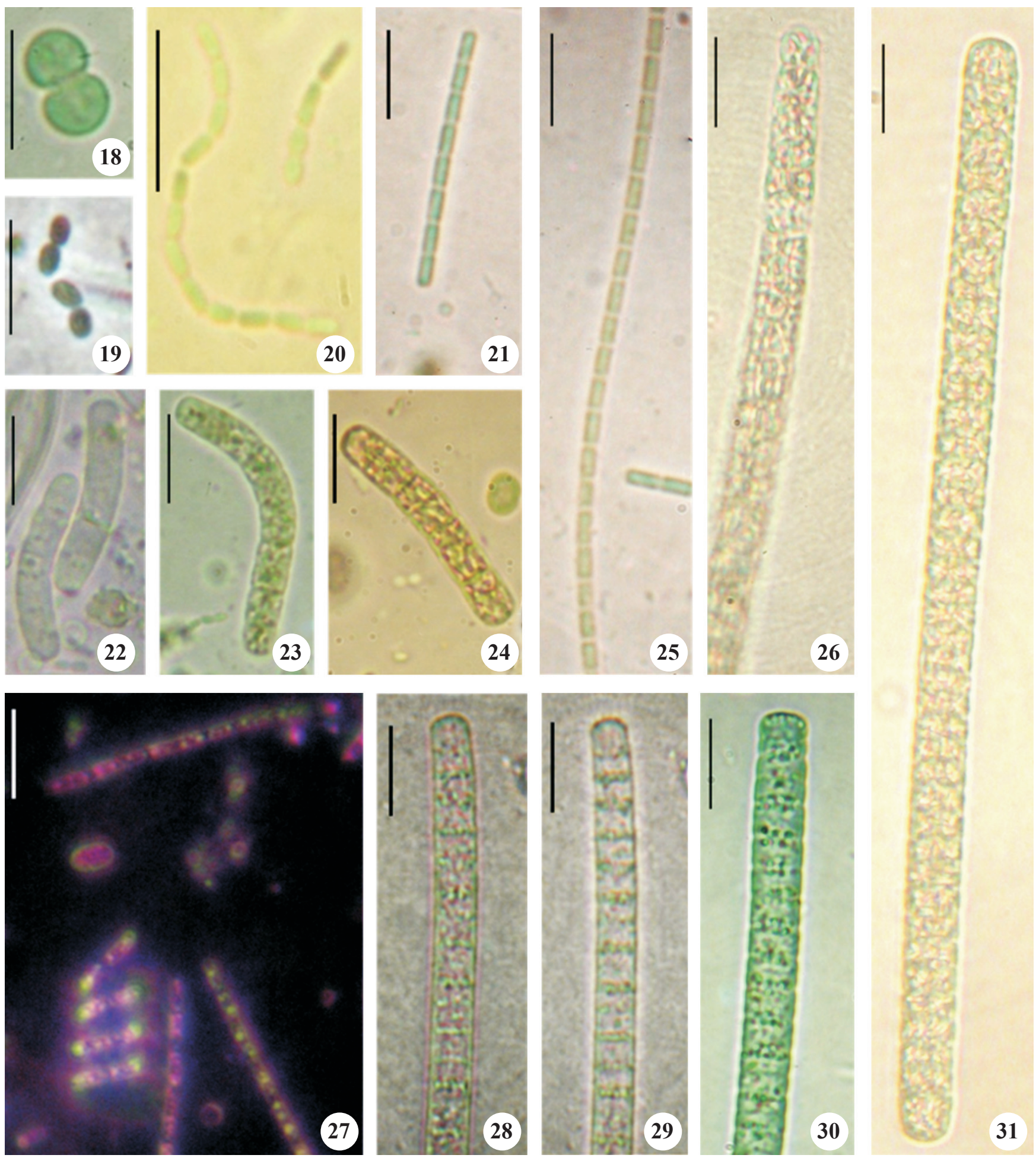

Figuras 18-31. 18. Synechocystis aquatilis. 19. Synechococcus $\mathrm{cf}$. nidulans. 20. Romeria victoriae. 21, 25. Pseudanabaena limnetica. 22-24. Prováveis hormogônios de Arthrospira platensis. 26. Planktothrix agardhii. 27. Eubactérias filamentosas e cocóides presentes na lagoa Salina do Meio (contraste de fase). 28-30. Phormidium tergestinum. 31. Planktothrix isothrix. Barras $=10 \mu \mathrm{m}$.

Figures 18-31. 18. Synechocystis aquatilis. 19. Synechococcus cf. nidulans. 20. Romeria victoriae. 21, 25. Pseudanabaena limnetica. 22-24. Probable hormogonia of Arthrospira platensis. 26. Planktothrix agardhii. 27. Filamentous and coccoids Eubacteria in lake Salina do Meio (phase contrast). 28-30. Phormidium tergestinum. 31. Planktothrix isothrix. Bars $=10 \mu \mathrm{m}$. 
primeiramente reconhecida por Komárek \& Kling (1991), para o Lago Victoria (África), sob a denominação de “Pseudanabaena/Romeria sp.”. Komárek \& Cronberg (2001) afirmam que estudos recentes registraram ampla distribuição de $R$. victoriae nos grandes reservatórios do sudeste da África e que esta espécie provavelmente ocorreria também em outras regiões tropicais.

\section{CHROOCOCCALES}

\section{CYANOBACTERIACEAE}

Myxobaktron sp.

Figura 5

Células isoladas ou aos pares, alongadas e afiladas nas extremidades, 3,8-12 $\mu \mathrm{m}$ compr., 0,7-1,5 $\mu \mathrm{m}$ larg.; envelope mucilaginoso ausente; conteúdo celular verde azulado, sem aerótopos.

Material examinado: BRASIL. Mato Grosso do Sul: Corumbá, Pantanal da Nhecolândia, Salina do Meio, 25-IX-2005, K.R.S. Santos \& C.F.S. Malone s.n. (SP390917).

O gênero Myxobaktron Schmidle é de ocorrência rara e inclui apenas três espécies que ocorrem no plâncton estuarino de água salobra e no metafíton de água doce (Sant'Anna et al. 2006). Segundo Komárek \& Anagnostidis (1999), trata-se de um gênero mal delimitado que necessita ainda de revisão taxonômica.

O material estudado difere das espécies descritas do gênero principalmente em relação às medidas celulares e hábito. A espécie mais próxima morfologicamente é Myxobaktron hirudiforme G. S. West. No entanto, em $M$. hirudiforme as células são maiores (30-62 $\mu \mathrm{m}$ compr.) e mais largas (1,8-2 $\mu \mathrm{m}$ larg.) e ocorre no metafiton de lagoas de água doce em Angola (Komárek \& Anagnostidis 1999), enquanto o material do Pantanal além de menores dimensões celulares foi encontrado no plâncton em lagoa de água salobra (Salina do Meio).

\section{SPIRULINACEAE}

\section{Glaucospira sp.}

Figura 32

Tricomas solitários, curtos, regular ou irregularmente espiralados, não constritos, não atenuados ou apenas levemente atenuados nos ápices, 17-40 $\mu \mathrm{m}$ compr., 1,2-2,0 $\mu \mathrm{m}$ diâm.; espiras não agregadas entre si, 2,5$4 \mu \mathrm{m}$ altura, distância entre as espiras 6-14 $\mu \mathrm{m}$; bainha ausente; conteúdo celular verde azulado, homogêneo, não granuloso; tricomas móveis, em rotação nos dois sentidos.
Material examinado: BRASIL. Mato Grosso do SuL: Corumbá, Pantanal da Nhecolândia, Salina do Meio, 25IX-2005, K.R.S. Santos \& C.F.S. Malone s.n. (SP390917); 28-VIII-2006, K.R.S. Santos s.n. (SP390916); 4-V-2007, K.R.S. Santos s.n. (SP390927).

De acordo com Komárek \& Anagnostidis (2005), Glaucospira Lagerh. é um gênero pouco conhecido e bastante problemático por não apresentar características bem definidas. A maioria das populações descritas pertence provavelmente a Eubacteria. No entanto, os mesmos autores afirmam que populações similares são encontradas na natureza especialmente sob condições extremas, e destacam a necessidade da revisão taxonômica do gênero.

Os exemplares do Pantanal ocorreram apenas na lagoa Salina do Meio em amostra fitoplanctônica nos períodos de seca e de cheia, sendo mais comuns no período de seca, ocasião em que as condições ambientais nesta lagoa eram ainda mais extremas: $\mathrm{pH}>9$, condutividade elétrica $>3.800 \mu \mathrm{S} \mathrm{cm}^{-1}$ e salinidade $>2$ ups, dados bastante elevados quando comparados às condições das outras lagoas estudadas (tabela 2). Com auxílio da epifluorescência, observou-se que o material estudado de fato é uma cianobactéria. No entanto, nessa mesma lagoa (Salina do Meio) foi observado, principalmente nos períodos de seca, grande quantidade de eubactérias filamentosas e cocóides (figura 27), que muitas vezes confundem-se com cianobactérias. A ocorrência deste táxon apenas na Salina do Meio corrobora as observações feitas por Komárek \& Anagnostidis (2005). Estudos mais detalhados do bacterioplâncton dessa lagoa precisam ser realizados já que este grupo constitui importante componente da biota desse sistema.

Spirulina subsalsa Gomont, Ann. Sci. nat. Sér. 7, 16: 253. 1892.

Figuras 37-38

Tricomas solitários, longos, até $220 \mu \mathrm{m}$ compr., densamente espiralados, não atenuados, não constritos, 1,8-2 $\mu \mathrm{m}$ de diâm.; espiras tocando-se em toda sua extensão, 4,6-4,8 $\mu \mathrm{m}$ altura; conteúdo celular verde azul claro, homogêneo ou granuloso; aerótopos ausentes.

Material examinado: BRASIL. MATo Grosso DO Sul: Corumbá, Pantanal da Nhecolândia, Salina do Meio, 22-IV-2006, K.R.S. Santos s.n. (SP390919); Salitrada Campo Dora, 17-XI-2006, K.R.S. Santos s.n. (SP390925).

De acordo com Werner (2002), Spirulina subsalsa é uma espécie bem caracterizada e distingue-se das demais espécies do gênero por apresentar tricomas densamente 
espiralados e suas espiras tocam-se em toda a extensão do tricoma. Conforme a referida autora, esta espécie já foi citada no Brasil para água doce e salobra, ocorrendo no plâncton, metafíton e também sobre o solo. Komárek \& Anagnostidis (2005) comentam que a espécie ocorre em biótopos marinhos, águas salgadas e salobras, freqüentemente em águas minerais e termais, algumas vezes em água doce.

Os exemplares do Pantanal ocorreram em água salobra e levemente salobra e são semelhantes aos encontrados por Werner (2002) em lagoas costeiras do Rio Grande do Sul e estão de acordo com a circunscrição da espécie documentada em Komárek \& Anagnostidis (2005).

Spirulina subtilissima Gomont, Ann. Sci. Nat. Bot. Sér. 7, 16: 252. 1892.

Figura 33

Tricomas solitários, longos, até $100 \mu \mathrm{m}$ compr., regularmente espiralados, não atenuados, não constritos, 0,6-0,8 $\mu \mathrm{m}$ diâm.; espiras frouxamente arranjadas, não se tocando entre si, 1,8-2,0 $\mu \mathrm{m}$ altura, distância entre as espiras 1,8-2,2 $\mu \mathrm{m}$; conteúdo celular verde azulado, homogêneo não granuloso.

Material examinado: BRASIL. MAto Grosso DO Sul: Corumbá, Pantanal da Nhecolândia, Salina do Meio, 28-VIII-2006, K.R.S. Santos s.n. (SP390916).

\section{OSCILLATORIALES}

\section{PHORMIDIACEAE}

Arthrospira platensis (Nordstedt) Gomont, Ann. Sci. Nat. Bot. Sér. 7, 16: 247. 1892. 三 Spirulina jenneri var. platensis Nordst., in Wittr. \& Nordst. Algae aquae dulcis exsicc. 21, 679: 59. 1844.

Figuras 8-11, 22-24, 41

Tricomas solitários, regularmente espiralados, constritos ou não, geralmente longos, 35-151(-371) $\mu \mathrm{m}$ compr., altura das espiras 16-32,4 $\mu \mathrm{m}$, distância entre as espiras 22-40,6 $\mu \mathrm{m}$, geralmente sem envelopemucilaginoso; células geralmente mais curtas que largas a subquadráticas, algumas mais longas que largas, 1,7-5,3(-9) $\mu \mathrm{m}$ compr., 4-7,8 $\mu \mathrm{m}$ larg., $\mathrm{Rc} / \mathrm{l}=0,5-1,3$; células apicais arredondadas, levemente atenuadas, raramente dilatadas, sem caliptra; conteúdo celular verde azulado, granuloso; aerótopos presentes, alongados, parietais.

Material examinado: BRASIL. Mato Grosso do Sul: Corumbá, Pantanal da Nhecolândia, Salina do Meio, 25-IX-2005, K.R.S. Santos \& C.F.S. Malone s.n. (SP390917), 22-IV-2006, K.R.S. Santos S.n. (SP390919),
28-VIII-2006, K.R.S. Santos s.n. (SP390922), 4-V-2007, K.R.S. Santos s.n. (SP390927); Salitrada Campo Dora, 17-XI-2006, K.R.S. Santos s.n. (SP390925).

De acordo com a descrição original de $A$. platensis, os tricomas não são atenuados ou apenas levemente, variam de 6-8 $\mu \mathrm{m}$ de larg., altura das espiras de 26-36 $\mu \mathrm{m}$ e distância entre as espiras de $43-57 \mu \mathrm{m}$; células aproximadamente isodiamétricas, 2-6 $\mu \mathrm{m}$ de compr. com protoplasma granuloso (Gomont 1892b). Observa-se que o autor não menciona a ocorrência ou não de aerótopos nesta espécie. Komárek \& Lund (1990) afirmam que $A$. platensis é tipicamente bentônica e não apresenta aerótopos. No entanto, de acordo com a revisão do gênero realizada por Jeeji-Bai (1999), A. platensis apresenta tricomas de 5-7 $\mu \mathrm{m}$ de larg., gradualmente e distintivamente atenuados para os ápices, células apicais frequentemente subcapitadas a distintivamente captadas, mas sem caliptra e protoplasma com aerótopos.

No presente estudo, observou-se ampla variação morfológica dos tricomas: ápices gradualmente atenuados (figura 11) ou não atenuados (figuras 8, 10); células apicais arredondadas, geralmente com menor largura que as células do centro do tricoma (figura 9), algumas mais largas, dilatadas (figura 8), mas sem formação de calíptra. Aerótopos estiveram presentes em praticamente todos os indivíduos (figura 41) e foi comum a ocorrência de grânulos distribuídos por todo o tricoma (figura 10). Prováveis hormogônios de A. platensis (figuras 22-24) foram encontrados em amostras da lagoa Salina do Meio e da Salitrada Campo Dora, em períodos de seca e de cheia. São tricomas curtos (até 13 células), constritos, retos ou curvos, com ou sem aerótopos. Essas formas foram mais abundantes na Salitrada Campo Dora, na amostra de novembro/2006 (época de cheia). Nesta ocasião havia pequena quantidade de água na lagoa, proveniente de chuva recente. Esta lagoa secou totalmente nos meses anteriores e esses hormogônios de A. platensis provavelmente são as primeiras formas de cianobactérias a se desenvolverem na lagoa.

A análise dessas populações indica que os caracteres morfológicos desta espécie devem ser ampliados, uma vez que para toda a variação morfológica observada foram encontradas formas intermediárias, demonstrando plena relação entre si. Assim, o presente material está de acordo com a circunscrição original apresentada por Gomont (1892b) acrescida dos caracteres observados por Jeeji-Bai (1999), principalmente em relação à presença de aerótopos. Além dessas informações, a presença de mucilagem fina e hialina (observada somente com adição de nanquim) é adicionada as características de A. platensis (figura 10). 



Figuras 32-41. 32. Glaucospira sp. 33. Spirulina subtilissima. 34-36, 39-40. Phormidium sp. 35. Tricoma com protoplasma diferenciado. 36, 39-40. Tricomas com necrídios (setas). 37-38. Spirulina subsalsa. 41. Arthrospira platensis. Barras $=10 \mu \mathrm{m}$.

Figures 32-41. 32. Glaucospira sp. 33. Spirulina subtilissima. 34-36, 39-40. Phormidium sp. 35. Trichome with differentiated cell content. 36, 39-40. Trichomes with necridic cells (arrow). 37-38. Spirulina subsalsa. 41. Arthrospira platensis. Bars $=10 \mu \mathrm{m}$. 
Phormidium tergestinum (Gomont) Anagnostidis \& Komárek, Algol. Studies 80: 406. 1988. 三Oscillatoria tenuis var. tergestina Gomont. Ann. Sci. Nat. Bot. Sér. 7, 15: 221. 1892.

Figuras 28-30

Tricomas solitários, retos ou levemente curvos, longos, até 2,3 mm compr., não constritos a levemente constritos, não atenuado para os ápices; bainha ausente; células quadráticas a subquadráticas, 3,1-6,9 $\mu \mathrm{m}$ compr., 4,6-6 $\mu \mathrm{m}$ larg., $\mathrm{Rc} / 1=0,6-1,3$; células apicais cilíndrico-arredondadas; conteúdo celular verde azulado, com grânulos evidentes nos septos.

Material examinado: BRASIL. Mato Grosso DO Sul: Corumbá, Pantanal da Nhecolândia, Baía da Sede Nhumirim, 28-VIII-2006, K.R.S. Santos s.n. (SP390923), 4-V-2007, K.R.S. Santos s.n. (SP390929).

Phormidium tergestinum assemelha-se morfologicamente a P. irriguum (Gomont) Anagnostidis \& Komárek, mas difere nas dimensões celulares e forma da célula apical. P. tergestinum apresenta tricomas com menores dimensões celulares e célula apical não diferenciada (figura 19), enquanto P. irriguum apresenta maiores dimensões celulares (4-11 $\mu \mathrm{m}$ compr., 6-11 $\mu \mathrm{m}$ larg.) e possui célula apical levemente captada com espessamento na parede celular (Gomont 1892a, Komárek \& Anagnostidis 2005). O presente material foi encontrado no plâncton e metafíton, sempre com tricomas isolados, o que difere da literatura, que cita $P$. tergestinum formando massas finas verde azuladas (Komárek \& Anagnostidis 2005, McGregor 2007). De acordo com Komárek \& Anagnostidis (2005), P. tergestinum apresenta ampla variação morfológica documentada em literatura e seu valor taxonômico necessita revisão.

\section{Phormidium sp.}

Figuras 12-16, 34-36, 39-40

Tricomas solitários, retos ou com extremidades apicais curva, longos, até 3,6 mm de compr., levemente constritos, levemente atenuados para um ou ambos os ápices, às vezes não atenuados; células isodiamétricas a mais longas que largas ou mais largas que longas, 5,7-10 $\mu \mathrm{m}$ compr., 5-8,1 $\mu \mathrm{m}$ larg., $\mathrm{Rc} / 1=0,8-1,7$; células apicais cônico-arredondadas ou arredondadas; conteúdo celular verde azulado, granuloso, às vezes com 1-2 grânulos grosseiros por célula, raramente não granulado; fragmentação do tricoma por meio de necrídios.

Material examinado: BRASIL. Mato Grosso do Sul: Corumbá, Pantanal da Nhecolândia, Baía da Sede Nhumirim, 28-VIII-2006, K.R.S. Santos s.n. (SP390923), 4-V-2007, K.R.S. Santos s.n. (SP390929).
O material do Pantanal apresentou ampla variação morfológica, principalmente no que se refere à granulação do tricoma. Observou-se que os indivíduos com grânulos maiores e mais evidentes ocorreram principalmente no período de seca, enquanto os não granulados ou com grânulos menos pronunciados ocorreram no período de cheia. Em alguns tricomas, uma das extremidades apresentou uma célula maior (24,6-154,6 $\mu \mathrm{m}$ compr., 5-7,6 $\mu \mathrm{m}$ larg.) constituída de uma rede de protoplasma (?) espiralado ou irregularmente arranjado, de coloração verde azul pálido (figuras 12-13, 35). Futuros estudos ultraestruturais são fundamentais para elucidar a origem destas células diferenciadas. $\mathrm{Na}$ tabela 3 são apresentadas as principais características de Phormidium sp. e das espécies mais próximas, conforme a literatura.

Comparando os espécimes estudados com as espécies mais próximas do gênero Phormidium, verificou-se que os mesmos são bem distintos, o que nos permite inferir que provavelmente trata-se de uma espécie nova para a ciência. No entanto, serão necessários estudos moleculares e ultra-estruturais para a precisa delimitação deste táxon. População encontrada apenas na Baía da Sede Nhumirim em amostras fitoplanctônica/metafíticas, em períodos de seca e de cheia.

Planktothrix agardhii (Gomont) Anagnostidis \& Komárek, Algol. Studies 80: 414-416. 1988. 三 Oscillatoria agardhii Gomont, Ann. Sci. Nat., Bot. Sér. 7. 16: 205. 1892.

Figura 26

Tricomas solitários, retos, longos, às vezes curvos no ápice, atenuados gradativamente em pelo menos uma das extremidades, levemente constritos; bainha ausente; células mais largas que longas a subquadráticas, 2,8-4,9 $\mu \mathrm{m}$ compr., 3,8-6,0 $\mu \mathrm{m}$ larg., Rc/1 = 0,3-0,9; conteúdo celular verde acastanhado; aerótopos alongados, distribuídos irregularmente por todo protoplasma; células apicais cônico-arredondadas, geralmente capitadas, às vezes com caliptra.

Material examinado: BRASIL. MATO GRosso DO Sul: Corumbá, Pantanal da Nhecolândia, Baía da Sede Nhumirim, 28-VIII-2006, K.R.S. Santos s.n. (SP390923), 16-XI-2006, K.R.S. Santos s.n. (SP390926), 4-V-2007, K.R.S. Santos s.n. (SP390929).

Komárek \& Anagnostidis (2005) comentam que Planktothrix agardhii é uma espécie amplamente distribuída em regiões temperadas com poucos registros em regiões tropicais e ocorre no plâncton de lagos e empoçados de água doce, podendo formar florações. 
Tabela 3. Principais características morfométricas de Phormidium sp. e táxons relacionados.

Table 3. Main morphometric characteristics of Phormidium sp. and related taxa.

\begin{tabular}{|c|c|c|c|}
\hline & $\begin{array}{l}\text { Phormidium sp. } \\
\text { (presente trabalho) }\end{array}$ & $\begin{array}{l}\text { Phormidium formosum } \\
\text { (Komárek \& Anagnostidis 2005) }\end{array}$ & $\begin{array}{l}\text { Phormidium hamelii } \\
\text { (Komárek \& Anagnostidis 2005) }\end{array}$ \\
\hline Tricomas & $\begin{array}{l}\text { solitários, longos, retos } \\
\text { ou levemente curvos }\end{array}$ & em talos, longos, \pm retos & $\begin{array}{l}\text { solitários ou aglomerados } \pm \\
\text { ondulados ou retos }\end{array}$ \\
\hline Ápices & atenuados ou não & levemente atenuados & não atenuados \\
\hline Constrição & levemente constrito & constrito & distintamente constrito \\
\hline Célula apical & cônico-arredondada & $\begin{array}{l}\text { cônico-obtusa, cônico-arre- } \\
\text { dondada ou arredondada }\end{array}$ & arredondada sem caliptra \\
\hline $\begin{array}{l}\text { Espessamento da } \\
\text { célula apical }\end{array}$ & $\begin{array}{l}\text { ausente } \\
\text { (raramente com caliptra) }\end{array}$ & ausente & ausente \\
\hline Forma das células & $\begin{array}{l}\text { quadráticas a } \\
\text { subquadráticas }\end{array}$ & $\begin{array}{l}\text { isodiamétricas até } 2 \mathrm{x} \text { mais } \\
\text { curtas que largas }\end{array}$ & $\begin{array}{l}\text { isodiamétricas até } 1,5 \mathrm{x} \text { mais } \\
\text { longas que largas }\end{array}$ \\
\hline $\begin{array}{l}\text { Comprimento das } \\
\text { células }(\mu \mathrm{m})\end{array}$ & $5,7-10$ & (2) $2,5-5,6(6,2)$ & (3)6-8(12?) \\
\hline Largura $(\mu \mathrm{m})$ & $5-8,1$ & $(3,8) 4-6(6,5)$ & $(3,2) 4,8-5,7(6)$ \\
\hline $\mathrm{Rc} / 1$ & $0,8-1,7$ & $0,5-1$ & $0,75-1,5$ \\
\hline Conteúdo celular & $\begin{array}{l}\text { verde azulado, com ou } \\
\text { sem grânulos }\end{array}$ & $\begin{array}{l}\text { verde azul claro, verde oliva a } \\
\text { verde amarelado }\end{array}$ & verde azulado \\
\hline Septos & não granulados & geralmente granulados & não granulados \\
\hline Hábitat & $\begin{array}{l}\text { planctônico e metafítico } \\
\text { em lagoa de água doce } \\
\text { rica em macrófitas } \\
\text { (Pantanal) }\end{array}$ & $\begin{array}{l}\text { perifítico e bentônico em águas } \\
\text { salobras, salinas e poluídas com } \\
\text { esgoto } \\
\text { (cosmopolita) }\end{array}$ & $\begin{array}{l}\text { em água doce, principalmente } \\
\text { na zona litorânea de águas } \\
\text { estagnadas, em arrozais, entre } \\
\text { outras algas (Pantropical) }\end{array}$ \\
\hline
\end{tabular}

Atualmente, esta espécie é freqüentemente citada como formadora de florações em reservatórios brasileiros (Sant'Anna et al. 2007, 2008).

Planktothrix isothrix (Skuja) Komárek \& Komárková, Czech Phycology 4: 14. 2004. $\equiv$ Oscillatoria agardhii var. isothrix Skuja, Symb. Bot. Upsal. 9(3): 49. 1948. Figura 31

Tricomas solitários, retos, geralmente longos, às vezes levemente curvos no ápice, não ou apenas levemente atenuados, levemente constritos; bainha ausente; células mais largas que longas 1,6-4 $\mu \mathrm{m}$ compr., 5,7-7,1 $\mu \mathrm{m}$ larg., $\mathrm{Rc} / 1=0,3-0,6$; conteúdo celular verde azulado, às vezes com pequenos grânulos esparsos; aerótopos irregulares, distribuídos por todo protoplasma; células apicais cilíndrico-arredondadas, não captadas, sem caliptra.

Material examinado: BRASIL. Mato Grosso do Sul: Corumbá, Pantanal da Nhecolândia, Baía da Sede Nhumirim, 28-VIII-2006, K.R.S. Santos S.n. (SP390923),
16-XI-2006, K.R.S. Santos s.n. (SP390926), 4-V-2007, K.R.S. Santos s.n. (SP390929).

A população estudada difere da descrição de Komárek \& Komárková (2004) e Komárek \& Anagnostidis (2005) para Planktothrix isothrix pelo grau de constrição do tricoma. Tipicamente a espécie apresenta tricomas não ou muito levemente constritos nos septos, enquanto o material do Pantanal apresentou sempre tricomas levemente constritos.

Komárek \& Anagnostidis (2005) afirmam que $P$. isothrix ocorre em água doce, com hábito primariamente bentônico, epipélico, secundariamente planctônico, solitário, frequentemente formando florações, distribuída mundialmente em águas estagnadas e lagos eutróficos a hipereutróficos.

\section{NOSTOCALES}

\section{NOSTOCACEAE}

Anabaenopsis cunningtonii Taylor, Amer. J. Botany 19: 461. Pl. 39, figs. 1-4. 1932. 
Figuras 42-43

Tricomas solitários, curtos, 8-18 células, retos a levemente curvos, constritos, não atenuados para os ápices; envelope mucilaginoso hialino, estreito ou ausente; células em forma de barril, região de contato achatada, isodiamétricas, mais curtas que largas ou mais longas que largas, 1,9-4,2 $\mu \mathrm{m}$ compr., 2,3-3,2 $\mu \mathrm{m}$ larg., $\mathrm{Rc} / 1=0,7-1,7$; conteúdo celular homogêneo, verde azul claro; aerótopos ausentes; heterocitos terminais, esféricos, 2,1-2,5 $\mu \mathrm{m}$ diâm., com pré-heterocito intercalar; acineto não observado.

Material examinado: BRASIL. Mato Grosso do SuL: Corumbá, Pantanal da Nhecolândia, Salitrada Campo Dora, 8-V-2005, K.R.S. Santos s.n. (SP390914).

Anabaenopsiscunningtonii foidescrita originalmente com as seguintes dimensões celulares: tricomas de 110-333 $\mu \mathrm{m}$ compr.; células de 11,1-16,4 $\mu \mathrm{m}$ compr., 2,2-3,8 $\mu \mathrm{m}$ larg.; heterocitos de 6,6-10,3 $\mu \mathrm{m}$ compr., 4,7-6,6 $\mu \mathrm{m}$ larg. (Taylor 1932).

O material do Pantanal apresenta células muito mais curtas (1,9-4,2 $\mu \mathrm{m}$ compr.) do que o descrito originalmente para a espécie, mas quanto à largura celular (2,3-3,2 $\mu \mathrm{m}$ larg.), a população analisada concorda perfeitamente com o descrito por Taylor (1932).

Jeeji-Bai et al. (1977), num trabalho de revisão do gênero Anabaenopsis (Wolosz.) Miller, estudaram material de cultura e concluíram que o comprimento das células de $A$. cunningtonii foi bastante variável, apresentando células desde mais curtas que largas até mais longas que largas, ou ainda arredondadas, dependendo das concentrações dos principais elementos essenciais no meio. Esses autores comentam também que a variação na largura celular não foi considerável $(3-4,6(5,4) \mu \mathrm{m})$ e os heterocitos eram normalmente esféricos, alguns ovais ou mais raramente alongados. No material estudado, também foi observado grande variação apenas no comprimento celular.

Anabaenopsis elenkinii Miller, Arch. Soc. Russ. Prot. 2: 125, figs. 1-5. 1923.

Figuras 44-51

Tricomas solitários, curtos, 2-12 células, curvos, raramente retos, formando 0-1,5 volta completa, constritos, não atenuados; envelope mucilaginoso hialino ou ausente; células cilíndricas, elípticas, com extremidades arredondadas, achatadas nos pontos de contato, 4,7-9 $\mu \mathrm{m}$ compr., 3-6 $\mu \mathrm{m}$ larg., $\mathrm{Rc} / \mathrm{l}=(1,1-) 1,2-2$; conteúdo celular verde-azul claro, granuloso; aerótopos presentes; heterocitos esféricos, 3-5 $\mu \mathrm{m}$ diâm.; acinetos elípticos a arredondados, 1-2, intercalares, 8,0-9,0 $\mu \mathrm{m}$ compr., 6,4-8,0 $\mu \mathrm{m}$ larg.

Material examinado: BRASIL. Mato Grosso DO Sul: Corumbá, Pantanal da Nhecolândia, Salina do Meio, 10-V-2004, K.R.S. Santos s.n. (SP390907); 14-X-2004, K.R.S. Santos s.n. (SP390910); 8-V-2005, K.R.S. Santos s.n. (SP390913), 28-VI-2005, A.Y. Sakamoto s.n. (SP390916), 25-IX-2005, K.R.S. Santos \& C.F.S. Malone s.n. (SP390917), 21-IV-2006, K.R.S. Santos s.n. (SP390919), 28-VIII-20006, K.R.S. Santos s.n. (SP390922), 16-XI-2006, K.R.S. Santos s.n. (SP390924), 4-V-2007, K.R.S. Santos s.n. (SP390927); Baía da Sede Nhumirim, 16-XI-2006, K.R.S. Santos S.n. (SP390926); Salitrada Campo Dora, 8-V-2005, K.R.S. Santos s.n. (SP390914).

De acordo com as revisões do gênero realizadas por Jeeji-Bai et al. $(1977,1980)$ a partir da análise de diferentes espécies planctônicas provenientes da Hungria e Peru e de culturas isoladas de material obtido no lago Hemmelsdorf (Alemanha), dentre as espécies de Anabaenopsis com tricomas espiralados e constritos, apenas A. magma Evans, A. arnoldii Aptekarj e A. elenkinii Miller, com suas formas taxonômicas, são reconhecidas como boas espécies. Os demais táxons do gênero foram considerados expressões morfológicas de uma dessas espécies.

Anabaenopsis elenkinii é uma espécie tropical de ambientes preferencialmente salinos e alcalinos, frequentemente encontradana comunidadefitoplanctônica dos lagos salinos e alcalinos da África (Komárek 2005, Ballot et al. 2008).

Os exemplares do Pantanal apresentaram características morfométricas semelhantes às descritas originalmente para a espécie (células 4,6-5,7 $\mu \mathrm{m}$ larg., Rc/1 = 1,25-2; heterocitos, 4,6-6,7; acinetos, 9,3-12 $\mu \mathrm{m}$ compr., 8,3-10,7 $\mu \mathrm{m}$ larg.) (Jeeji-Bai et al. 1977, 1980).

No presente trabalho $A$. elenkinii ocorreu em todas as amostras da lagoa Salina do Meio, sendo abundante tanto nos períodos de cheia quanto de seca. Florações deste táxon foram observadas no período de seca (outubro de 2004) e no período de cheia (maio de 2007) associado a Craticula buderi (Hust.) Lange-Bert. (Bacillariophyceae). Nas lagoas Salitrada Campo Dora e Baía da Sede Nhumirim a espécie ocorreu em apenas uma amostra com poucos indivíduos.

O presente estudo corrobora as observações feitas por Santos et al. (2004) de que Anabaenopsis possa ser um indicador de lagoas salinas do Pantanal da Nhecolândia e mostra que $A$. elenkinii é uma espécie comum nas lagoas salinas (água salobra) e muito rara ou até ausente nas baías e salitradas (água doce) do Pantanal da Nhecolândia. Devido à sua importância ecológica nas 

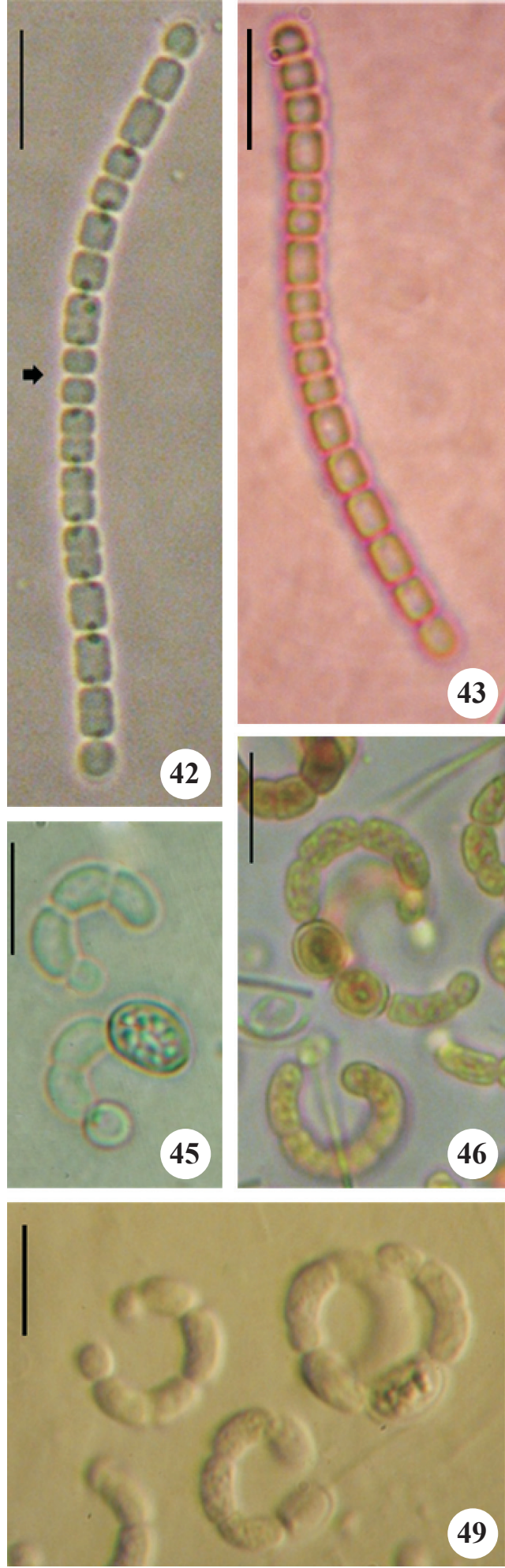

43

46
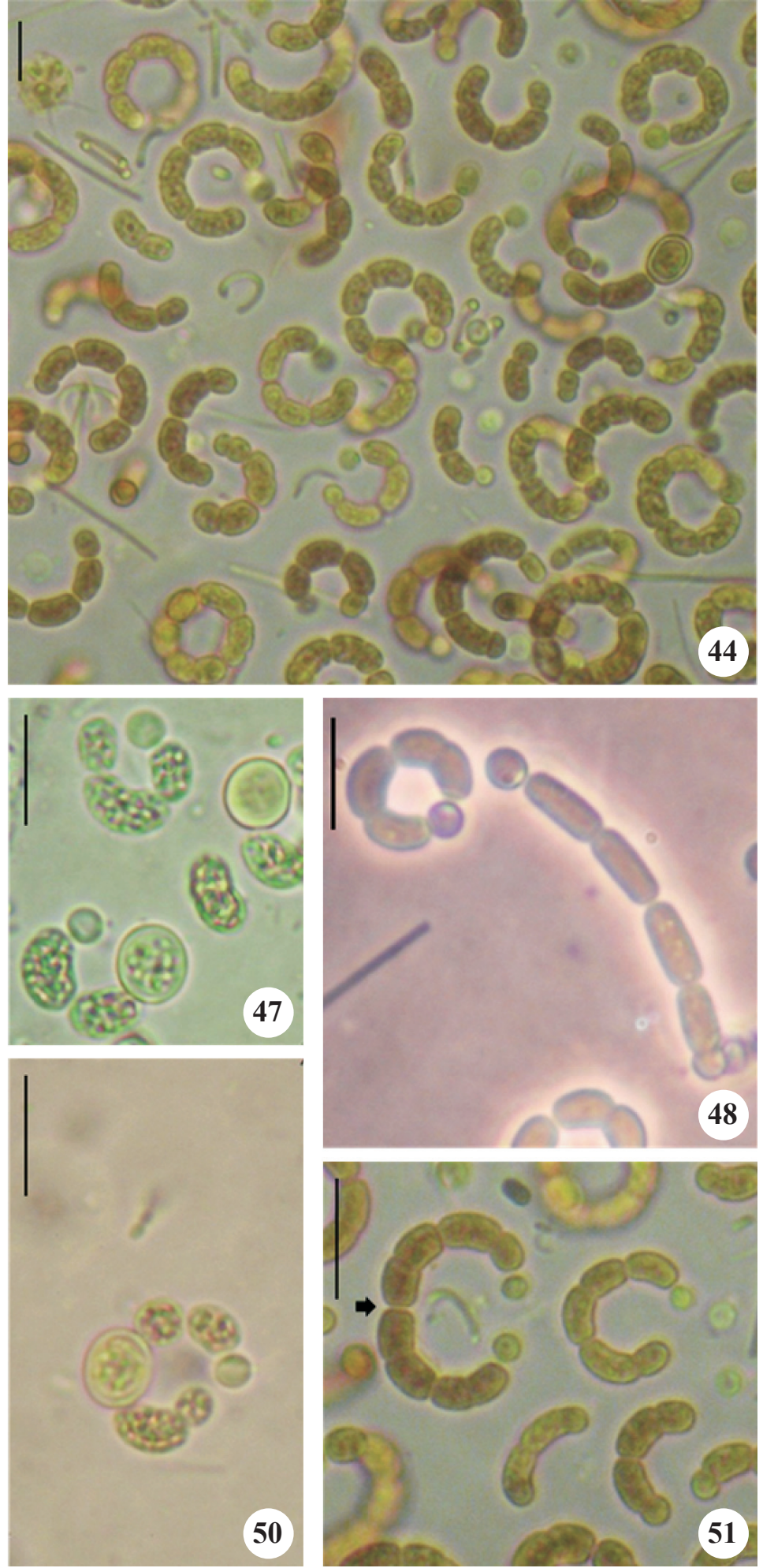

Figuras 42-51. 42-43. Anabaenopsis cunningtonii. 42. Formação de pró-heterocito (seta). 44-51. Anabaenopsis elenkinii. 44. Floração mostrando variabilidade morfológica dos tricomas (Salina do Meio). 48. Tricoma reto (ocorrência rara). 45-47, 49-50. Forma dos acinetos. 51. Região de formação de pró-heterocito (seta). Barras $=10 \mu \mathrm{m}$.

Figures 42-51. 42-43. Anabaenopsis cunningtonii. 42. Pro-heterocite formation (arrow). 44-51. Anabaenopsis elenkinii. 44. Bloom showing morphological variation of trichomes (Salina do Meio). 48. Straight trichome (rare occurrence). 45-47, 49-50. Akinetes shape. 51. Region of pro-heterocite formation (arrow). Bars $=10 \mu \mathrm{m}$. 
lagoas salinas, estudos de desenvolvimento em cultura são extremamente interessantes para avaliar o potencial biotecnológico de $A$. elenkinii.

\section{Aphanizomenon/Anabaena}

Figuras 52-62

Tricomas solitários ou aglomerados, retos ou curvos, geralmente longos, constritos, atenuados em pelo menos um dos ápices; envelope mucilaginoso ausente ou inconspícuo e hialino nas células vegetativas, ao redor dos heterocitos bainha rígida, esverdeada, espessa ca. 1,5 $\mu \mathrm{m}$; células vegetativas cilíndricas, hemiesféricas, subquadráticas a quadráticas ou em forma de barril, 2,5-5,2(-7) $\mu \mathrm{m}$ compr., 2,5-4,1 $\mu \mathrm{m}$ larg., Rc/1 = $0,7-1,5(-2,5)$, células apicais geralmente hialinas e atenuadas, não ou apenas levemente alongadas, 3,8-7 $\mu \mathrm{m}$ compr., 2,5-3,5 $\mu \mathrm{m}$ larg.; conteúdo celular verde azulado, sem grânulos; aerótopos concentrados na região central da célula; parede celular espessa, verde azulada; heterocitos com distribuição metamérica, oblongos, levemente alongados ou sub-esféricos 5,1-7 $\mu \mathrm{m}$ compr., 4,7-5,3 $\mu \mathrm{m}$ larg., $\mathrm{Rc} / 1=(1-) 1,1-1,5$; acinetos não observados.

Material examinado: BRASIL. Mato Grosso Do Sul: Corumbá, Pantanal da Nhecolândia, Baía da Sede Nhumirim, 28-VIII-2006, K.R.S. Santos s.n. (SP390923).

De acordo com Hindák (2000), a posição taxonômica dos gêneros Aphanizomenon Bornet \& Flahault e Anabaena Bornet \& Flahault tem sido objeto de debate. As características principais do gênero Aphanizomenon, de acordo com Komárek \& Kovácik (1989), são: tricomas com estrutura subsimétrica, atenuados nas extremidades; células apicais alongadas, geralmente hialinas; heterocitos subterminais solitários. O gênero Anabaena, de acordo com Komárek \& Anagnostidis (1989), é caracterizado por apresentar tricomas metaméricos, heterocitos sempre intercalares, solitários, que ocorrem em intervalos mais ou menos regulares; tricomas não ou apenas muito levemente atenuados; células apicais arredondadas ou levemente atenuadas.

Komárek \& Kovácik (1989) comentam que ápices atenuados também ocorrem em algumas espécies de Anabaena e afirmam que esta característica constituise em um caráter secundário na taxonomia do gênero Aphanizomenon, o que dificulta a delimitação precisa entre esses táxons. Conforme observado por Melcher (2007), em trabalho de revisão dos gêneros Aphanizomenon, Cylindrospermopsis Seen. \& Subba Raju e Raphidiopsis Fritsch \& Rich com base em análises morfológicas, moleculares e toxicológicas de cepas isoladas de várias regiões do Brasil, o gênero Aphanizomenon é bastante problemático do ponto de vista taxonômico, uma vez que também pode apresentar características típicas do gênero Anabaena (células esféricas, estrutura metamérica do tricoma). Além disso, Rajaniemi et al. (2005), com base nos genes rpo B e rrs, verificaram a polifilia de ambos os gêneros, intermisturados nas árvores filogenéticas.

Komárek \& Kovácik (1989), ao estudarem material da Tchecoslováquia (atualmente República Checa e Eslováquia), identificaram quatro grupos de espécies de Aphanizomenon ("a", "b", "c" e "d"). As características dos exemplares do Pantanal assemelham-se ao grupo "d", que inclui alguns indivíduos planctônicos de Anabaena, caracterizado por apresentar tricomas solitários, com aerótopos, claramente afilados para os ápices, mas sem célula apical alongada. O posicionamento deste grupo em relação a Anabaena ou Aphanizomenon permanece em aberto (Komárek \& Kovácik 1989). A população estudada é comparável também ao gênero Trichormus (Bornet \& Flahault) Komárek \& Anagnostidis, porém a ausência de acinetos inviabilizou a identificação correta deste táxon. O gênero Trichormus apresenta acinetos apoheterocíticos (entre dois heterocitos), o que o diferencia de Anabaena (acinetos paraheterocíticos - ao lado dos heterocitos). Rajaniemi et al. (2005) mostram que Trichormus é um gênero pofilético e que há ainda necessidade de melhor delimitação de suas espécies, inclusive em termos moleculares.

Estudos futuros com consequente observação de acinetos, aliados a estudos moleculares são necessários para esclarecer o posicionamento mais adequado deste táxon em relação aos gêneros mencionados. A tabela 4 apresenta as principais características do material analisado comparado com os táxons mais próximos encontrados na literatura.

\section{RIVULARIACEAE}

Calothrix cf. flahaultii Frémy, Arch. de Bot., S. 5, fig. 1. 1927.

Figura 17

Tricomas longos, ca. $425 \mu \mathrm{m}$ compr., retos ou levemente curvos, levemente constritos, atenuados gradativamente em direção à extremidade, porção basal quase cilíndrica, muito levemente espessada, 5,5-5,7 $\mu \mathrm{m}$ larg. na base, 4-4,6 $\mu \mathrm{m}$ larg. na região mediana, 2,2-3,4 $\mu \mathrm{m}$ larg. nas células terminais; ápice geralmente terminando em pêlo hialino; células mais curtas que largas a subquadráticas na porção basal e mediana, 2-7,2 $\mu \mathrm{m}$ compr., $\mathrm{Rc} / 1=0,3-1,3$, células mais longas que largas na extremidade, em forma de pêlo hialino, 


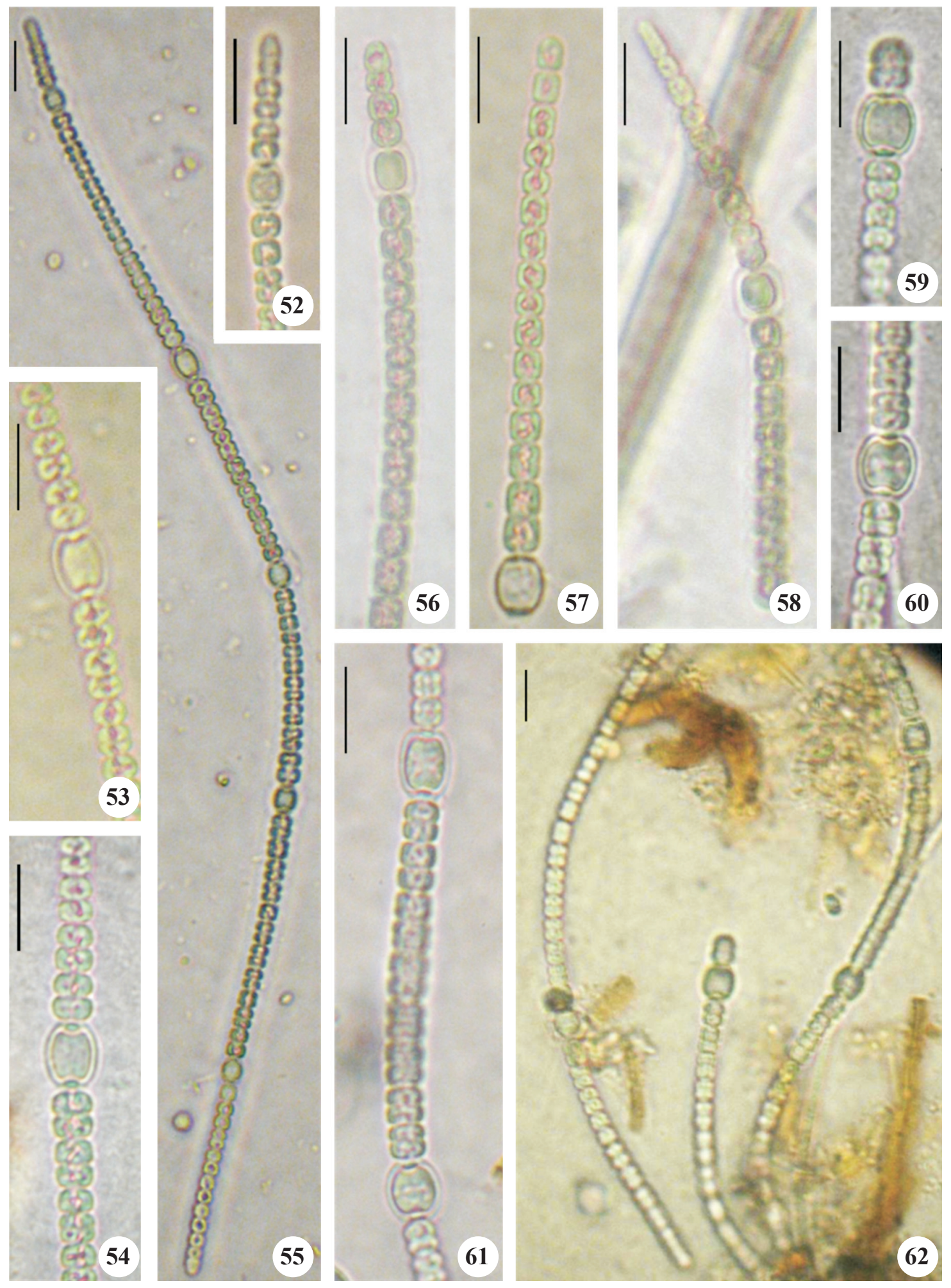

Figuras 52-62. Aphanizomenon/Anabaena. 55. Tricoma isolado com heterocitos submetaméricos. 56-59. Tricomas levemente atenuados, heterocitos em forma de barril, aerótopos concentrados no centro das células. 62 . Tricomas aglomerados no metafíton. Barras $=10 \mu \mathrm{m}$.

Figures 52-62. Aphanizomenon/Anabaena. 55. Trichome solitary displaying submetameric heterocites. 56-59. Trichomes slightly attenuated, barrel shaped heterocites, aerotopes concentrated in cells center. 62. Metaphytic entangled trichomes. Bars $=10 \mu \mathrm{m}$. 
Tabela 4. Principais características morfométricas de Aphanizomenon/Anabaena e táxons relacionados. (Abreviações: irreg. = irregularmente; lev. = levemente).

Table 4. Main morphometric characteristics of Aphanizomenon/Anabaena and related taxa.

\begin{tabular}{|c|c|c|c|c|c|}
\hline & $\begin{array}{l}\text { Aphanizomenon/ } \\
\text { Anabaena } \\
\text { (presente trabalho) }\end{array}$ & $\begin{array}{l}\text { Anabaena bergii } \\
\text { (Hindák 2000) }\end{array}$ & $\begin{array}{l}\text { A. bergii var. } \\
\text { minor } \\
\text { (Hindák 2000) }\end{array}$ & $\begin{array}{l}\text { A. bergii var. } \\
\text { limnetica } \\
\text { (Hindák 2000) }\end{array}$ & $\begin{array}{l}\text { Aph. gracile } \\
\text { (Komárek \& } \\
\text { Kovácik 1989) }\end{array}$ \\
\hline Tricoma & $\begin{array}{l}\text { solitário ou aglomerado, } \\
\text { reto ou curvo }\end{array}$ & $\begin{array}{l}\text { solitário, reto ou } \\
\text { lev. curvo }\end{array}$ & $\begin{array}{l}\text { solitário, reto } \\
\text { ou lev. curvo }\end{array}$ & $\begin{array}{l}\text { solitário, reto } \\
\text { ou lev. curvo }\end{array}$ & $\begin{array}{l}\text { solitário, reto ou } \\
\text { lev. curvo }\end{array}$ \\
\hline $\begin{array}{l}\text { Estrutura do } \\
\text { tricoma }\end{array}$ & simétrico sub-simétrico & simétrico & simétrico & $\begin{array}{l}\text { simétrico } \\
\text { sub-simétrico }\end{array}$ & sub-simétrico \\
\hline Aerótopos & $\begin{array}{l}\text { presentes concentrados } \\
\text { no centro da célula }\end{array}$ & $\begin{array}{l}\text { presentes } \\
\text { dispersos irreg. }\end{array}$ & $\begin{array}{l}\text { presentes } \\
\text { dispersos irreg. }\end{array}$ & $\begin{array}{l}\text { presentes } \\
\text { dispersos irreg. }\end{array}$ & $\begin{array}{l}\text { presentes } \\
\text { dispersos irreg. }\end{array}$ \\
\hline Forma da célula & barril, arredondada & barril, sub-esférica & esférica & barril & \pm alongada \\
\hline $\begin{array}{l}\text { Comprimento da } \\
\text { célula }(\mu \mathrm{m})\end{array}$ & $2,5-5,2(7)$ & - & - & $2,5-6$ & $(2,6) 2,8-6,4(7,1)$ \\
\hline Largura $(\mu \mathrm{m})$ & $2,5-4,1$ & $5-7$ & $4,2-6,5$ & $3,5-5,5(7)$ & $(2,3) 2,6-3,1(3,7)$ \\
\hline Célula apical & cônico-arredondada & - & - & - & alongada \\
\hline $\begin{array}{l}\text { Comprimento da } \\
\text { célula apical ( } \mu \mathrm{m})\end{array}$ & $2,5-5,2(7)$ & - & - & - & $(3,6) 4,3-6,4(7,4)$ \\
\hline $\begin{array}{l}\text { Forma do } \\
\text { heterocito }\end{array}$ & oblongo ou subesférico & $\begin{array}{l}\text { esférico a } \\
\text { amplamente ovalado }\end{array}$ & - & - & alongado \\
\hline $\begin{array}{l}\text { Comprimento do } \\
\text { heterocito }(\mu \mathrm{m})\end{array}$ & $5,1-7$ & - & $4,5-6,5$ & $4,5-9$ & $(3,9) 7,8(9,8)$ \\
\hline Largura $(\mu \mathrm{m})$ & $4,7-5,3$ & $7-8$ & $5-6,5$ & $5-8$ & $3,4-4,9(5,9)$ \\
\hline Forma do acineto & - & $\begin{array}{l}\text { amplamente ovalado } \\
\text { a esférico }\end{array}$ & - & - & cilíndrico, alongado \\
\hline $\begin{array}{l}\text { Comprimento do } \\
\text { acineto }(\mu \mathrm{m})\end{array}$ & - & $14-18$ & $13-16$ & (13)19-32 & $(6,4) 7,8-14,7(16,7)$ \\
\hline Largura $(\mu \mathrm{m})$ & - & $10-15$ & $11-12$ & $11-14$ & $(2,9) 3,9-5,9(6,4)$ \\
\hline Hábitat & $\begin{array}{l}\text { plâncton e metafíton em } \\
\text { lagoa de água doce rica } \\
\text { em macrófitas (Pantanal) }\end{array}$ & $\begin{array}{l}\text { plâncton, descrito } \\
\text { para água salobra }\end{array}$ & $\begin{array}{l}\text { plâncton, água } \\
\text { salina, Mar } \\
\text { Cáspio e Aral }\end{array}$ & $\begin{array}{l}\text { plâncton, lagoas } \\
\text { e rios de água } \\
\text { doce, França }\end{array}$ & $\begin{array}{l}\text { plâncton, água doce, rio } \\
\text { Danúbio e reservatório } \\
\text { próximo de Trëbon }\end{array}$ \\
\hline
\end{tabular}

13,7-36 $\mu \mathrm{m}$ compr., Rc/1=4-16,4; bainha mucilaginosa hialina, tênue ou até ausente; aerótopos ausentes; heterocito basal, esférico, ca. $9 \mu \mathrm{m}$ diâmetro.

Material examinado: BRASIL. Mato Grosso do Sul: Corumbá, Pantanal da Nhecolândia, Salitrada Campo Dora, 8-V-2005, K.R.S. Santos s.n. (SP390914).

Calothrix flahaultii Frémy foi descrita originalmente como ocorrendo em grupo de 3-9 tricomas, com heterocito basal cilíndrico alongado e com as seguintes dimensões celulares: 5,5-6,5 $\mu \mathrm{m}$ larg. na base, 4-5 $\mu \mathrm{m}$ larg. na porção mediana, com células quadráticas até 1,5 vezes mais longas do que largas (Geitler 1932). O material do Pantanal difere da descrição original por apresentar heterocito basal esférico, mas as demais características, como forma do tricoma e dimensões celulares, são similares ao descrito para a espécie. Este táxon foi encontrado isolado em meio a espécimes de Oedogonium spp., e ocorreu apenas na lagoa Salitrada Campo Dora, em amostra fitoplanctônica/ metafítica no período de cheia.

Foram identificadas 21 espécies de cianobactérias, distribuídas em cinco ordens, oito famílias e quinze gêneros. As Oscillatoriales foram as mais bem representadas em número de espécies (5, correspondendo a $24 \%$ do total), seguida das ordens Synechococcales, Pseudanabaenales, Chroococcales e Nostocales, cada uma contribuindo com quatro espécies (19\%). A Salina do Meio apresentou a maior riqueza de espécies (13), enquanto a Salitrada Campo Dora e Baía da Sede Nhumirim apresentaram nove táxons cada uma (tabela 5, figura 63).

As condições extremas da lagoa Salina do Meio, isto é, $\mathrm{pH}>9$ e condutividade elétrica $>3.000 \mu \mathrm{S} \mathrm{cm}^{-1}$, certamente deixaram as cianobactérias sem competidores, 
Tabela 5. Biodiversidade e distribuição de cianobactérias nas lagoas estudadas do Pantanal da Nhecolândia, MS, Brasil.

Table 5. Biodiversity and distribution of Cyanobacteria in the studied lakes from Pantanal da Nhecolândia, Mato Grosso do Sul State, Brazil.

\begin{tabular}{|c|c|c|c|}
\hline & Salina do Meio & Salitrada Campo Dora & Baía da Sede Nhumirim \\
\hline \multicolumn{4}{|l|}{ SYNECHOCOCCALES } \\
\hline \multicolumn{4}{|l|}{ MERISMOPEDIACEAE } \\
\hline Coelomoron tropicale & & + & \\
\hline Synechocystis aquatilis & + & + & \\
\hline \multicolumn{4}{|l|}{ SYNECHOCOCCACEAE } \\
\hline Synechococcus cf. nidulans & + & & + \\
\hline Synechococcus sigmoideus & + & & + \\
\hline \multicolumn{4}{|l|}{ PSEUDANABAENALES } \\
\hline \multicolumn{4}{|l|}{ PSEUDANABAENACEAE } \\
\hline Jaaginema subtilissimum & + & & \\
\hline Pseudanabaena limnetica & + & + & \\
\hline Romeria caruaru* & + & & \\
\hline Romeria victoriae & + & + & + \\
\hline \multicolumn{4}{|l|}{ CHROOCOCCALES } \\
\hline \multicolumn{4}{|l|}{ CYANOBACTERIACEAE } \\
\hline Myxobaktron sp. & + & & \\
\hline \multicolumn{4}{|l|}{ SPIRULINACEAE } \\
\hline Glaucospira sp. & + & & \\
\hline Spirulina subsalsa & + & + & \\
\hline Spirulina subtilissima & + & & \\
\hline \multicolumn{4}{|l|}{ OSCILLATORIALES } \\
\hline \multicolumn{4}{|l|}{ PHORMIDIACEAE } \\
\hline Arthrospira platensis & + & + & \\
\hline Phormidium tergestinum & & & + \\
\hline Phormidium sp. & & & + \\
\hline Planktothrix agardhii* & & & + \\
\hline Planktothrix isothrix* & & & + \\
\hline \multicolumn{4}{|l|}{ NOSTOCALES } \\
\hline \multicolumn{4}{|l|}{ NOSTOCACEAE } \\
\hline Anabaenopsis cunningtonii & & + & \\
\hline Anabaenopsis elenkinii & + & + & + \\
\hline Aphanizomenon/Anabaena & & & + \\
\hline \multicolumn{4}{|l|}{ RIVULARIACEAE } \\
\hline Calothrix cf. flahaultii & & + & \\
\hline
\end{tabular}

*Espécies potencialmente tóxicas (Cronberg \& Annadotter 2006, Komárek et al. 2001)

já que a maioria das algas e mesmo as macrófitas, não se desenvolvem nestes ambientes. Assim, as cianobactérias constituem o grupo com maior riqueza de espécies na Salina do Meio, exatamente por ser o grupo mais adaptado a estas condições extremas.

As outras lagoas estudadas apresentaram condições mais favoráveis ao desenvolvimento de vários grupos de organismos (algas e macrófitas) o que certamente, aumentou a competição com relação às cianobactérias, resultando menor riqueza de espécies desse grupo na Salitrada Campo Dora e na Baía da Sede Nhumirim.

A dominância de cianobactérias observada na Salina do Meio, com destaque para Anabaenopsis elenkinii que forma florações principalmente nos períodos de seca, 


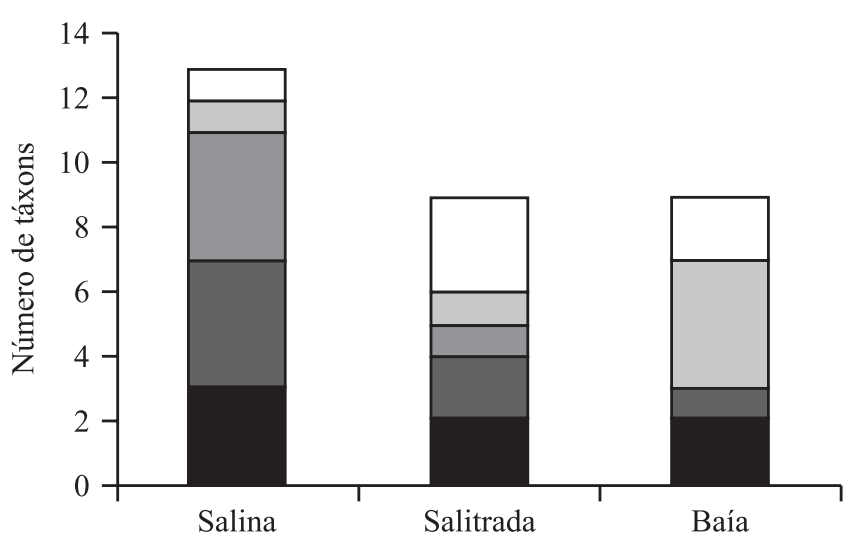

Figura 63. Biodiversidade de cianobactérias em três lagoas do Pantanal da Nhecolândia, MS, Brasil. Número total de táxons e número de táxons das Ordens Synechococcales ( $\square)$, Pseudanabaenales ( $\square$ ), Chroococcales ( $\square$ ), Oscillatoriales $(\square)$ e Nostocales ( $\square$ ), em cada lagoa.

Figure 63. Biodiversity of Cyanobacteria in three lakes from Pantanal da Nhecolândia, Mato Grosso do Sul State, Brazil. Total number of taxa and number of taxa of the Orders Synechococcales ( $\square$ ), Pseudanabaenales $(\square)$, Chroococcales ( $\square$ ), Oscillatoriales ( $\square$ ) and Nostocales ( $\square$ ), in each lake.

demonstra a importância da realização de estudos futuros de desenvolvimento em cultura, para avaliar o potencial tóxico e biotecnológico desta espécie. Arthrospira platensis também foi uma espécie comum na Salina do Meio e Salitrada Campo Dora. As duas espécies são naturalmente encontradas em águas salobras de regiões tropicais, como os lagos alcalinos (pH 11) da África, com alta concentração de $\mathrm{NaCl}$ e bicarbonatos (Ballot et al. 2008, Jeeji-Bai et al. 1980, Volkmann et al. 2008).

Anabaenopsis elenkinii e Romeria victoriae são espécies conhecidas de ambientes salinos (salobros) e alcalinos da África e foram as únicas espécies comuns às três lagoas estudadas no Pantanal da Nhecolândia, o que indica serem tolerantes a ampla variação de $\mathrm{pH}$, condutividade e salinidade. Essas espécies foram mais abundantes nas amostras da Salina do Meio (água salobra), e apenas eventualmente foram encontradas na Salitrada Campo Dora (água doce a levemente salobra) e Baía da Sede Nhumirim (água doce). As espécies de cianobactérias específicas de cada lagoa (tabela 5) evidenciam as particularidades desses ambientes (salina, salitrada e baía).

Entre as 21 espécies identificadas de cianobactérias, três (Planktothrix agardhii, P. isothrix e Romeria caruaru) são consideradas potencialmente tóxicas, o que representa $14,3 \%$ do total. O estudo das três lagoas mostrou alto percentual (100\%) de novas ocorrências de espécies para a região do Pantanal brasileiro, evidenciando a necessidade de desenvolver mais trabalhos de levantamento florístico e conservação da biodiversidade, já que milhares de outros habitats aquáticos deste bioma não foram ainda estudados.

Agradecimentos - Os autores agradecem ao Programa de Pós Graduação em Biodiversidade Vegetal e Meio Ambiente do Instituto de Botânica (IBt, SP) e à Universidade Federal de Mato Grosso do Sul (UFMS), especialmente ao prof. Dr. Arnaldo Yoso Sakamoto (UFMS Campus de Três Lagoas), pela logística disponibilizada nas expedições de coleta. Ao Conselho Nacional de Desenvolvimento Científico e Tecnológico (CNPq, Brasil), pela bolsa de mestrado concedida ao primeiro autor.

\section{Referências bibliográficas}

ALMEIDA, T.I.R., SÍGOLO, J.B., FERNANDES, E., QUEIROZNETO, J.P., BARBIERO, L. \& SAKAMOTO, A.Y. 2003. Proposta de classificação e gênese das lagoas da Baixa Nhecolândia - MS com base em sensoriamento remoto e dados de campo. Revista Brasileira de Geociências 33:83-90.

BALLOT, A., DADHEECH, P.K., HAANDE, S. \& KRIENITZ, L. 2008. Morphological and phylogenetic analysis of Anabaenopsis abijatae and Anabaenopsis elenkinii (Nostocales, Cyanobacteria) from tropical inland water bodies. Microbial Ecology 55:608-618.

BRUM, P.A.R. \& SOUSA, J.C. 1985. Níveis de nutrientes para gado, em lagoas ("baías" e "salinas") no Pantanal Sul-Mato-Grossense. Pesquisa Agropecuária Brasileira 20:1451-1454.

CALHEIROS, D.F. \& OLIVEIRA, M.D. 1999. Pesquisa limnológica no Pantanal: uma revisão. In Anais do II Simpósio sobre Recursos Naturais e Sócio-econômicos do Pantanal (B.M.A. Soriano, coord.). Embrapa Pantanal, Corumbá, p.115-125.

CRONBERG, G. \& ANNADOTTER, H. 2006. Manual on aquatic cyanobacteria: a photo guide and a synopsis of their toxicology. International Society for the Study of Harmful Algae and United Nations Educational, Scientific and Cultural Organisation. Copenhagen.

DE-LAMONICA-FREIRE, E.M. \& HECKMAN, C.W. 1996. The seasonal succession of biotic communities in wetlands of the tropical wet-and-dray climatic zone: III. The algal communities in the Pantanal of Mato Grosso, Brazil, with a comprehensive list of the known species and revision of two desmid taxa. Institut für Hydrobiologie und Fischereiwissenschaft 81:253-280.

DELAZARI-BARROSO, A., SANT'ANNA, C.L. \& SENNA, P.A.C. 2007. Phytoplankton from Duas Bocas Reservoir, Espírito Santo State, Brazil (except diatoms). Hoehnea 34:211-229. 
DOMITROVIC, Y.Z. 2002. Structure and variation of the Paraguay River phytoplankton in two periods of its hydrological cycle. Hydrobiologia 472:177-196.

DROUET, F. 1938. The Brazilian Myxophyceae, 2. American Journal of Botany 25:657-666.

EMBRAPA. CENTRO DE PESQUISA AGROPECUÁRIA DO PANTANAL. 1997. Plano de utilização da fazenda Nhumirim (B.M.A. Soriano, D.H. Oliveira, J.B. Catto, J.A. Comastri Filho, S. Galdino \& S.M. Salis, orgs.). Embrapa Pantanal, Documento 21, p.1-72.

GEITLER, L. 1932. Cyanophyceae. In Rabenhorst's Kryptogamenflora von Deutschland, Österreich und der Schweiz. 2. Aufl. Akademische Verlagsgesellschaft Leipzig, v.14, p.1-1196.

GOMONT, M.M. 1892a. Monographie des Oscillariées (Nostocacées homocytées). Annales Sciences Naturelles Botanique. Sér. 7, Paris, v.15, p.263-368.

GOMONT, M.M. 1892b. Monographie des Oscillariées (Nostocacées homocytées). Annales Sciences Naturelles Botanique. Sér. 7, Paris, v.16, p.91-264.

HAMILTON, S., SIPPEL, S.S.J., CALHEIROS, D.F. \& MELACK, J. 1999. Chemical characteristics of Pantanal waters. In Anais do II Simpósio sobre Recursos Naturais e Sócio-econômicos do Pantanal (B.M.A. Soriano, coord.). Embrapa Pantanal, Corumbá, p.89-100.

HINDÁK, F. 2000. Morphological variation of four planktic nostocalean cyanophytes - members of the genus Aphanizomenon or Anabaena? Hydrobiologia 438: 107-116.

HOFFMANN, L., KOMÁREK, J. \& KASTOVSKY, J. 2005. System of cyanoprokaryotes (cyanobacteria) - state in 2004. Algological Studies 117:95-115.

HONDA, R.Y. \& AZEVEDO, M.T.P. 2004. Estudos taxonômicos em culturas de Cyanobacteria provenientes de um reservatório oligotrófico no Parque Estadual das Fontes do Ipiranga (PEFI), São Paulo, SP, Brasil. Hoehnea 31:151-169.

JEEJI-BAI, N. 1999. A taxonomic revision of the genus Arthrospira based on certain new criteria. In Marine cyanobacteria (L. Charpy, \& A.W.D. Larkum, eds.). Bulletin of the Institute Oceanography. Monaco, special issue 19:47-52.

JEEJI-BAI, N., HEGEWALD, E. \& SOEDER, C.J. 1977. Revision and taxonomic analysis of genus Anabaenopsis. Algological Studies 18:25-32.

JEEJI-BAI, N., HEGEWALD, E. \& SOEDER, C.J. 1980. Taxonomic studies on the genus Anabaenopsis (Wolosz.) Miller. In Taxonomy of algae (T.V. Desikachary \& V.N. Rajarao, eds.) University of Madras, p.115-145.

KOMÁREK, J. 2005. Phenotypic diversity of the heterocytous cyanoprokaryotic genus Anabaenopsis. Czech Phycology 5:1-35.

KOMÁREK, J. \& ANAGNOSTIDIS, K. 1989. Modern approach to the classification system of cyanophytes. Nostocales 4. Algological Studies 56:247-345.
KOMÁREK, J. \& ANAGNOSTIDIS, K. 1999. Cyanoprokaryota. 1. Teil Chroococcales. In Süsswasserflora von Mitteleuropa (H. Ettl, G. Gärtner, H. Heying \& D. Möllenhauer, eds.). Gustav Fischer Verlag, Stuttgar, v.19. p.1-548.

KOMÁREK, J. \& ANAGNOSTIDIS, K. 2005. Cyanoprokaryota 2. Teil: Oscillatoriales. In Süsswasserflora von Mitteleuropa (B. Büdel, L. Krienitz, G. Gärtner \& M. Schagerl, eds.). Elsevier Spektrum Akademischer Verlag, München, v.19, p.1-759.

KOMÁREK, J., AZEVEDO, S.M.F.O., DOMINGOS, P., KOMÁRKOVÁ, J. \& TICHY, M. 2001. Background of the Caruaru tragedy; a case taxonomic study of toxic cyanobacteria. Algological Studies 103:9-29.

KOMÁREK, J.\& CRONBERG, G. 2001. Some chroococalean and oscillatorialean Cyanoprokaryotes from African lakes, ponds and pools. Nova Hedwigia 73:129-160.

KOMÁREK, J. \& KLING, H. 1991. Variation in six planktonic cyanophyte genera in Lake Victoria (East Africa). Algological Studies 61:21-45.

KOMÁREK, J. \& KOMÁRKOVÁ, J. 2004. Taxonomic review of the cyanoprokariotic genera Planktothrix and Planktothricoides. Czechoslovakia Phycology 4:1-18.

KOMÁREK, J. \& KOVÁCIK, L. 1989. Trichome structure of four Aphanizomenon taxa (Cyanophyceae) from Czechoslovakia, with notes on the taxonomy and delimitation of the genus. Plant Systematics and Evolution 164:47-64.

KOMÁREK, J. \& LUND, J.W.G. 1990. What is "Spirulina platensis" in fact? Algological Studies 58:1-13.

MCGREGOR, G.B. 2007. Freshwater Cyanoprokaryota of North-Eastern Australia. 1. Oscillatoriales. - Flora of Australia Supplementary Series № 24. Australian Biological Resources Study, Canberra.

MALONE, C.F.S, SANTOS, K.R.S, NETO, M.J. \& SAKAMOTO, A.Y. 2007. Gêneros de algas no plâncton de lagoas salinas situadas na fazenda Nhumirim, Pantanal da Nhecolândia, MS. Revista Brasileira de Biociências 5:588-590.

MEDINA-JUNIOR, P.B. \& RIETZLER, A.C. 2005. Limnological study of a Pantanal saline lake. Brazilian Journal of Biology 65:651-659.

MELCHER, S.S. 2007. Estudos morfológicos e moleculares de cianobactérias potencialmente tóxicas dos gêneros Aphanizomenon, Cylindrospermopsis e Raphidiopsis (Nostocales). Tese de doutorado. Instituto de Botânica, São Paulo.

MOURÃO, G.M. 1989. Limnologia comparativa de três lagoas (duas "baías" e uma "salina") do Pantanal da Nhecolândia, MS. Dissertação de mestrado, Universidade Federal de São Carlos. São Carlos.

MOURÃO, G.M., ISHII I.H. \& CAMPOS, Z.M.S. 1988. Alguns fatores limmnológicos relacionados com a ictiofauna de baías e salinas do Pantanal da Nhecolândia, MS, Brasil. Acta Limnologica Brasiliensia 2:181-198. 
OLIVEIRA, M.D. \& CALHEIROS, D.F. 2000. Flood pulse influence on phytoplankton communities of the south Pantanal floodplain, Brazil. Hydrobiologia 427: 101-112.

RAJANIEMI, P., HROUZE K, P., KASTOVSKÁ, K., WILLAME, R., RANTALA, A., HOFFMANN, L., KOMÁREK, J. \& SIVONEN, K. 2005. Phylogenetic and morphological evaluation of genera Anabaena, Aphanizomenon, Tricormus and Nostoc (Nostocales, Cyanobacteria). International Journal of Systematic and Evolutionary Microbiology 55:11-26.

REZENDE-FILHO, A.T. 2006. Estudo da variabilidade e espacialização das unidades da paisagem: Banhado (baía/ vazante), Lagoa Salina e Lagoa Salitrada no Pantanal da Nhecolândia, MS. Dissertação de mestrado. Universidade Federal de Mato Grosso do Sul, Aquidauana.

SANT'ANNA, C.L., BRANCO, L.H.Z. \& AZEVEDO, M.T.P. 2006. Cyanophyceae/Cyanobacteria. In Gêneros de Algas de Águas Continentais do Brasil (C.E.M. Bicudo \& M. Menezes, orgs.), 2 ed. Rima, p.19-84.

SANT'ANNA, C.L., MELCHER, S.S. \& CARVALHO, M.C. 2007. Planktic Cyanobacteria from upper Tietê basin reservoirs, SP, Brazil. Revista Brasileira de Botânica 30:1-17.

SANT'ANNA, C.L, AZEVEDO, M.T.P., WERNER, V.R., DOGO, C.R., RIOS, F.R. \& CARVALHO, LR. 2008. Review of toxic species of Cyanobacteria in Brazil. Algological Studies 126:249-263.

SANTOS, K.R.S. 2008. Biodiversidade de algas e cianobactérias de três lagoas ("salina", "salitrada" e "baía") do Pantanal da Nhecolândia, MS, Brasil. Dissertação de mestrado. Instituto de Botânica, São Paulo.

SANTOS, K.R.S., SAKAMOTO, A.Y., NETO, M.J., BARBIERO, L. \& QUEIROZ NETO, J.P. 2004. Ficoflora do Pantanal da Nhecolândia, MS, Brasil: um levantamento preliminar em três lagoas salinas e uma salitrada. In Anais do IV Simpósio sobre Recursos Naturais e Sócio-econômicos do Pantanal (J.R.B. Sereno, coord.). Embrapa Pantanal, Corumbá (meio eletrônico).

SENNA, P.A.C., PERES, A.C. \& KOMÁREK, J. 1998. Coelomoron tropicalis, a new cyanoprokaryotic species from São Paulo State, Brazil. Nova Hedwigia 67: 93-100.

SILVA, E.L.V., OLIVEIRA, M.D. \& ISHII, I.H. 2000. Estrutura da comunidade fitoplanctônica no Rio Paraguai e Canal do Tamengo, Pantanal, MS. In Anais do III Simpósio sobre Recursos Naturais e Sócio-econômicos do Pantanal (E.K. Rezende, A.O. Pellegrin, J.A.C. Filho \& L.A. Pellegrin, coords.). Embrapa Pantanal, Corumbá (meio eletrônico).

SILVA, J.S.V. \& ABDON, M.M. 1998. Delimitação do Pantanal brasileiro e suas sub-regiões. Pesquisa Agropecuária Brasileira 33:1703-1711.

SORIANO, B.M.A. 1999. Caracterização climática da subregião da Nhecolândia, Pantanal, MS. In Anais do II Simpósio sobre Recursos Naturais e Sócio-econômicos do Pantanal. Embrapa Pantanal (B.M.A. Soriano, coord.), Corumbá, p.151-158.

TAYLOR, W.R. 1932. Notes on the genus Anabaenopsis. American Journal of Botany 19:454-462.

VOLKMANN, H., IMIANOVSKY, U., OLIVEIRA, J.L.B. \& SANT'ANNA, E.S. 2008. Cultivation of Arthrospira (Spirulina) platensis in desalinator wastewater and salinated sinthetic médium: protein content and aminoacid profile. Brazilian Journal of Microbiology 39: 98-101.

WERNER, V.R. 2002. Cyanophyceae/Cyanobacteria no sistema de lagoas e lagunas da planície costeira do Estado do Rio Grande do Sul, Brasil. Tese de doutorado. Universidade Estadual Paulista, Rio Claro. 